$\frac{164}{4} /\left.10\right|^{30}$

DR. 1027

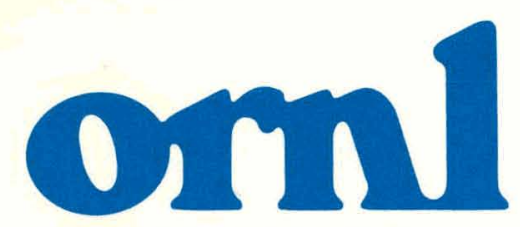

OAK

RIDGE

NATIONAL

LABORATORY

UNION

CARBIDE

\title{
Recent Improvements in Thomson Scattering Data Analysis
}

\author{
M. S. Tillack \\ E. A. Lazarus
}

OPERATED BY

UNION CARBIDE CORPORATION FOR THE UNITED STATES DEPARTMENT OF ENERGY 


\section{DISCLAIMER}

This report was prepared as an account of work sponsored by an agency of the United States Government. Neither the United States Government nor any agency Thereof, nor any of their employees, makes any warranty, express or implied, or assumes any legal liability or responsibility for the accuracy, completeness, or usefulness of any information, apparatus, product, or process disclosed, or represents that its use would not infringe privately owned rights. Reference herein to any specific commercial product, process, or service by trade name, trademark, manufacturer, or otherwise does not necessarily constitute or imply its endorsement, recommendation, or favoring by the United States Government or any agency thereof. The views and opinions of authors expressed herein do not necessarily state or reflect those of the United States Government or any agency thereof. 


\section{DISCLAIMER}

Portions of this document may be illegible in electronic image products. Images are produced from the best available original document. 
Printed in the United States of America. Available from National Technical Information Service

U.S. Department of Commerce

5285 Port Royal Road, Springfield, Virginia 22161

NTIS price codes-Printed Copy: A04; Microfiche A01

This report was prepared as an account of work sponsored by an agency of the United States Government. Neither the United States Government nor any agency thereof, nor any of their employees, makes any warranty, express or implied, or assumes any legal liability or responsibility for the accuracy, completeness, or usefulness of any information, apparatus, product, or process disclosed, or represents that its use would not infringe privately owned rights. Reference herein to any specific commercial product, process, or service by trade name, trademark, manufacturer, or otherwise, does not necessarily constitute or imply its endorsement, recommendation, or favoring by the United States Government or any agency thereof. The views and opinions of authors expressed herein do not necessarily state or reflect those of the United States Government or any agency thereof. 
ORNL/TM-7054

Dist. Category UC-20 f

Contract No. W-7405-eng-26

FUSION ENERGY DIVISION

RECENT IMPROVEMENTS IN THOMSON SCATTERING

DATA ANALYSIS

M. S. Tillack

Massachusetts Institute of Technology

Cambridge, Massachusetts 02139

E. A. Lazarus

Date Published - Apr1.1. 1.980

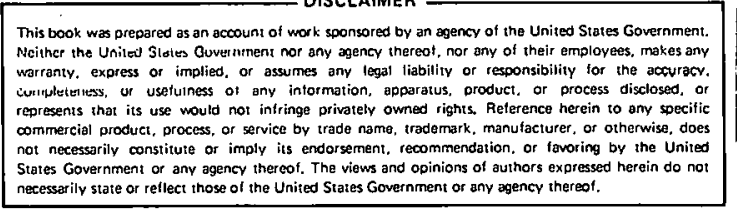

States Government of any agency thereof. The viows and opinions of authors expressed
necessarily state or reflect those of the United States Government or any agency therest.

NOTICE This document contains information of a preliminary nature.

It is subject to revision or correction and therefore does not represent a final report.

Prepared by the

OAK RIDGE NATIONAL LABORATORY

Oak Ridge, Tennessee 37830

operated by

UNION CARBIDE CORPORATION

for the

DEPARTMENT OF ENERGY 


\section{THIS PAGE}

WAS INTENTIONALLY

LEFT BLANK 


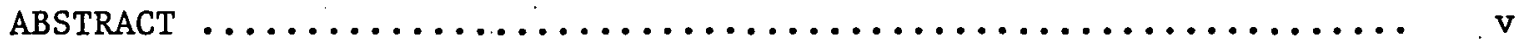

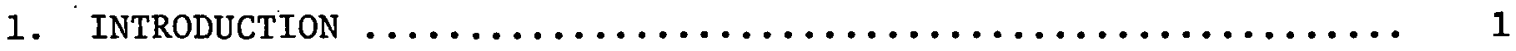

2. COMPARISON OF RESULTS ............................ 3

3. ERROR ANALYSIS/SENSITIVITY STUDY ..................... 8

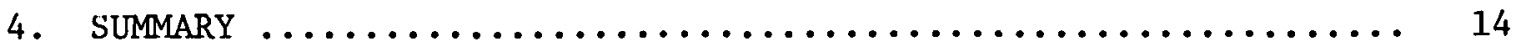
APPENDIXES

A. Detailed Description of the Data Analysis Package ......... 15

B. Flow Charts of PROFIT, ZIN, NEWRAP ................... 23

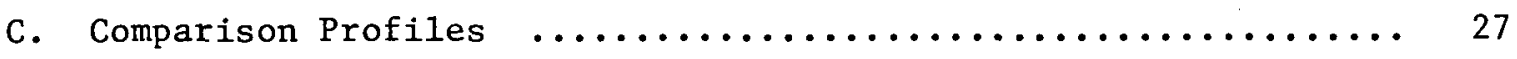

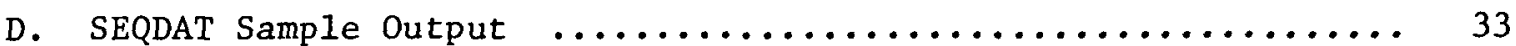

E. PROFIT Sample Output ............................... 39

F. PROFIL Sample Output ..............................45

G. ZORDIC Sample Dutput .............................. 49 


\section{THIS PAGE}

\section{WAS INTENTIONALLY \\ LEFT BLANK}




\section{ABSTRACT}

A new profile analysis package for use with the Thomson scattering data on ISX-B has recently been implemented. The primary feature of this package is a weighted least squares fitting of temperature and density data to generate a representative curve, as opposed to the previous hand-fitting technique. The changes will automate the manner in which data are transmitted and manipulated, without affecting the calculational techniques previously used. The computer programs have also been used to estimate the sensitivity of various plasma quantities Lo the accuracy of the lihomson scattering data. 


\section{INTRODUCTION}

SCAT PAK has been operating reliably for many years as an automated Thomson scattering data collection system. Currently, the electron temperature and density are scanned through 11 positions across the plasma radius (although the system has continuous scanning capability), yielding a profile with approximately 25 reproducible tokamak discharges. Through CAMAC hardware, these profiles are immediately available on the operating PDP-8.

However, until now the subsequent analysis of data has been delayed by the need to hand-fit and manually enter data for the calculational routines. ${ }^{*}$ This procedure can be tedious and time-consuming. Features of the new data handling proccdure that improve th1s condition are: automatic transmission of profiles from the PDP-8 to the PDP-10, computer fitting of profiles, and computer-assisted preparation of data for calculations.

Significant operational advantages are realized by automating the Thomson scattering data analysis. The time required for the analysis of a single profile has been reduced at least a factor of 5 . With the SCAT. PAK-II system (single-shot profiles), this increased speed will be a necessity. In addition, because most of the data input for calculations are now handled automatically, ${ }^{\dagger}$ the probability of reanalysis due to erroneous entry of data is virtually eliminated.

Besides the operational advantages, several nther benefits comc from the application of least squares fitting. (1) The fits are weighted by comblning statistical and calibration uncertainties to place errors on each data point in a laser sequence (both temperature and density).

\footnotetext{
* These data are classified into two categories: gross plasma conditions and plasma profiles. Gross plasma conditions include properties measured by diagnostics other than Thomson scattering; i.e., loop voltage, plasma current, toroidal field, etc. Plasma profiles are spatial measurements of electron temperature and density that result from scanning the Thomson scattering apparatus across the plasma in the radial direction.

tExceptions are ion temperature and neutral beam power.
} 
Weighting the fits improves their accuracy and allows for the transmission of uncertainties to all calculated quantities. (2) The consistency of approach implies more uniform results. The subjective properties of data analysis have been removed while still retaining the ability to make human decisions. (3) Least squares fitting to a recognizable analytical expression results in the generation of useful parameters concerning the shape of the profiles, which can be used to describe the plasma (see Appendix A). 


\section{COMPARISON OF RESULTS}

Most important to the conversion from one system to another is the fact that the final results are not drastically affected. To verify this the analysis of data has been repeated for experiments performed, and Table 1 summarizes some of the parameters of interest.

In addition to the final results, a comparison of the fits themselves determines the success of computer fitting (see Appendix $C$ ). In most cases the computer fit is very close.to, and at least as good as, the previously drawn hand-fit curves. It is important to note that the process of analysis is now capable of considerable flexibility for change and improvement. This approach is a step toward more sophisticated and (hopefully) better data analysis procedures. 
Table 1. Comparison of results (hand-fit profiles vs computer-fit profiles)

\begin{tabular}{|c|c|c|c|c|}
\hline \multicolumn{3}{|c|}{$Z_{\text {eff }}^{\prime}$} & \multicolumn{2}{|c|}{$\tau_{\mathrm{E}}(\mathrm{ms})$} \\
\hline Profile & Hand & Computer & Hand & Computer \\
\hline 052291-1 & 3.68 & 4.5 .4 & 18.1 & 18.8 \\
\hline $052291-\approx$ & 3.59 & $5 .<2$ & 14.7 & 15.8 \\
\hline $052492-1$ & 1.87 & 1.78 & 53.0 & 47.8 \\
\hline $052492-2$ & 1.62 & -.23 & 85.7 & 92.7 \\
\hline 060591-1 & 1.92 & 1.79 & 21.7 & 20.9 \\
\hline $060591-2$ & 1.49 & 1.51 & 23.4 & 27.7 \\
\hline $060791-1$ & 2.58 & 3.10 & 19.7 & 21.8 \\
\hline $060791-2$ & 1.94 & 1.37 & 18.1 & 19.1 \\
\hline 060792-1 & 2.53 & 1.92 & 30.6 & 30.6 \\
\hline $060792-2$ & 2.39 & 1.77 & 18.0 & 16.5 \\
\hline $060792-3$ & 3.41 & 2.82 & 9.5 & 10.3 \\
\hline 061091-1 & 1.77 & 1.23 & 105.3 & 97.4 \\
\hline 061091-2 & 1.10 & 1.09 & 57.0 & 53.3 \\
\hline
\end{tabular}


Table 1 (continued)

\begin{tabular}{|c|c|c|c|c|}
\hline \multicolumn{3}{|c|}{$\mathrm{W}_{\mathrm{e}}(\mathrm{kJ})$} & \multicolumn{2}{|c|}{$\mathrm{W}_{\mathrm{i}}(\mathrm{kJ})$} \\
\hline Profile & Hand & Computer & Hand & Computer \\
\hline $052291-1$ & 3.38 & 3.78 & 1.40 & 1.19 \\
\hline $052291-2$ & 3.54 & 3.57 & 1.58 & 1.35 \\
\hline $052492-1$ & 3.25 & 3.14 & 3.62 & 3.32 \\
\hline $052492-2$ & 3.65 & 3.21 & 4.84 & 5.97 \\
\hline 060591-1 & 1.68 & 1.53 & 1.72 & 1.74 \\
\hline $060591-2$ & 1.93 & $1.88^{\circ}$ & 2.21 & 3.03 \\
\hline $060791-1$ & 2.07 & 2.24 & 1.15 & 1.33 \\
\hline $060791-2$ & 2.16 & 1.90 & 1.69 & 2.18 \\
\hline $060792-1$ & 2.47 & 2.24 & 1.20 & 1.43 \\
\hline $060792-2$ & 1.66 & 1.44 & 0.65 & 0.68 \\
\hline $060792-3$ & 1.18 & 1.13 & 0.25 . & 0.42 \\
\hline 061091-1 & 3.25 & 2.79 & 2.72 & 2.73 \\
\hline $061091-2$ & 1.58 & 1.52 & 2.12 & 1.91 \\
\hline
\end{tabular}


Table 1 (continued)

\begin{tabular}{|c|c|c|c|c|}
\hline \multicolumn{3}{|c|}{$\left\langle\mathrm{T}_{\mathrm{e}}>(\mathrm{eV})\right.$} & \multicolumn{2}{|c|}{$q(a)$} \\
\hline Profile & Hand & Computer & Hand & Computer \\
\hline $052291-1$ & 3.42 & 4.00 & 2.72 & 2.56 \\
\hline $052291-2$ & 3.31 & 3.04 & 2.56 & 2.86 \\
\hline $052492-1$ & 5.74 & 5.58 & 3.83 & 4.00 \\
\hline 052492-2 & 6.13 & 4.85 & 3.76 & 4.00 \\
\hline 060591-1 & 2.37 & 2.28 & 3.89 & 3.57 \\
\hline 060591-2 & 2.39 & 1.84 & 4.01 & 4.01 \\
\hline $060791-1$ & 3.36 & 3.43 & 3.95 & 3.70 \\
\hline 060791-2 & 2.67 & 2.47 & 3.91 & 3.81 \\
\hline 060792-1 & 3.83 & 3.53 & 3.95 & 3.95 \\
\hline $060792-2$ & 3.86 & 3.21 & 3.67 & 3.67 \\
\hline $060792-3$ & 4.15 & 3.78 & 3.63 & 3.51 \\
\hline $06=091-1$ & 5.44 & 5.25 & 4.40 & 4.03 \\
\hline 06I091-2 & 4.04 & 3.92 & 4.27 & 4.05 \\
\hline
\end{tabular}


Table 1 (continued)

\begin{tabular}{llllll} 
& \multicolumn{3}{c}{$\beta_{\mathrm{T}}(0)(\%)$} & & \multicolumn{2}{c}{$\left\langle\beta_{\mathrm{T}}\right\rangle(\%)$} \\
\cline { 1 - 5 } Profile & Hand & Computer & & Hand & Computer \\
\hline $052291-1$ & 1.10 & 0.96 & 1.13 & 0.57 & 0.65 \\
$052291-2$ & 1.31 & 2.99 & 0.56 & 0.57 \\
$052492-1$ & 3.02 & 2.91 & 0.43 & 0.39 \\
$052492-2$ & 2.59 & 0.85 & 0.53 & 0.53 \\
$060591-1$ & 0.97 & 1.15 & 0.36 & 0.39 \\
$060591-2$ & 1.61 & 1.06 & 0.42 & 0.50 \\
$060791-1$ & 1.45 & 2.49 & 0.33 & 0.40 \\
$060791-2$ & 2.68 & 1.65 & 0.39 & 0.42 \\
$060792-1$ & 1.51 & 1.31 & 0.38 & 0.38 \\
$060792-2$ & 1.17 & 0.62 & 0.26 & 0.23 \\
$060792-3$ & 0.99 & 4.35 & 0.16 & 0.18 \\
$061091-1$ & 4.24 & 3.26 & 0.62 & 0.61 \\
$061091-2$ & 3.67 & & 0.41 & 0.39 \\
\hline
\end{tabular}




\section{ERROR ANALYSIS/SENSITIVITY STUDY}

One of the purposes for developing the computer fitting routines was to systematically generate uncertainties in calculated quantities, using the uncertainties in temperature and density values. Three methods of varying complexity were considered. The best method involves mapping the surface in parameter space that represents those combinations of parameters that increase $x^{2}$ by one over its minimum value. Each of these combinations must be used individually to generate profiles that are used in the calculations. Many sets of plasma properties would have to be calculated to procure the extreme values and this method would be pluhibitively time-consuming.

The correlations between the parameters could be overlooked by simultaneously extending each one by a standard deviation. However, this upper bound or the uncertainties is far too large.

Another method that still yields an upper bound (although a lower one than obtained from the above method) is to fit the error bars on the data. This is done by adding a standard deviation once to all of the data and also by subtracting. These Lwo fittcd curves provide an envelope bounding the best profile estimate. An upper bound is still produced as errors in real life should occur randomly in the positive and hegative directions. However, it was observed that these limits are murh more reasonable. It is this latter method that was employed to test the data taken and the results of which are compiled in Table 2. "Nominal" is the best fit. The other four comblnations are also listed (temperature and density plus standard deviation, temperature plus density minus, temperature and density minus standard deviation, and temperature minus density plus). Some typical profiles are shown in Figs. 1 and 2 . 
Table 2. Results of error analysis

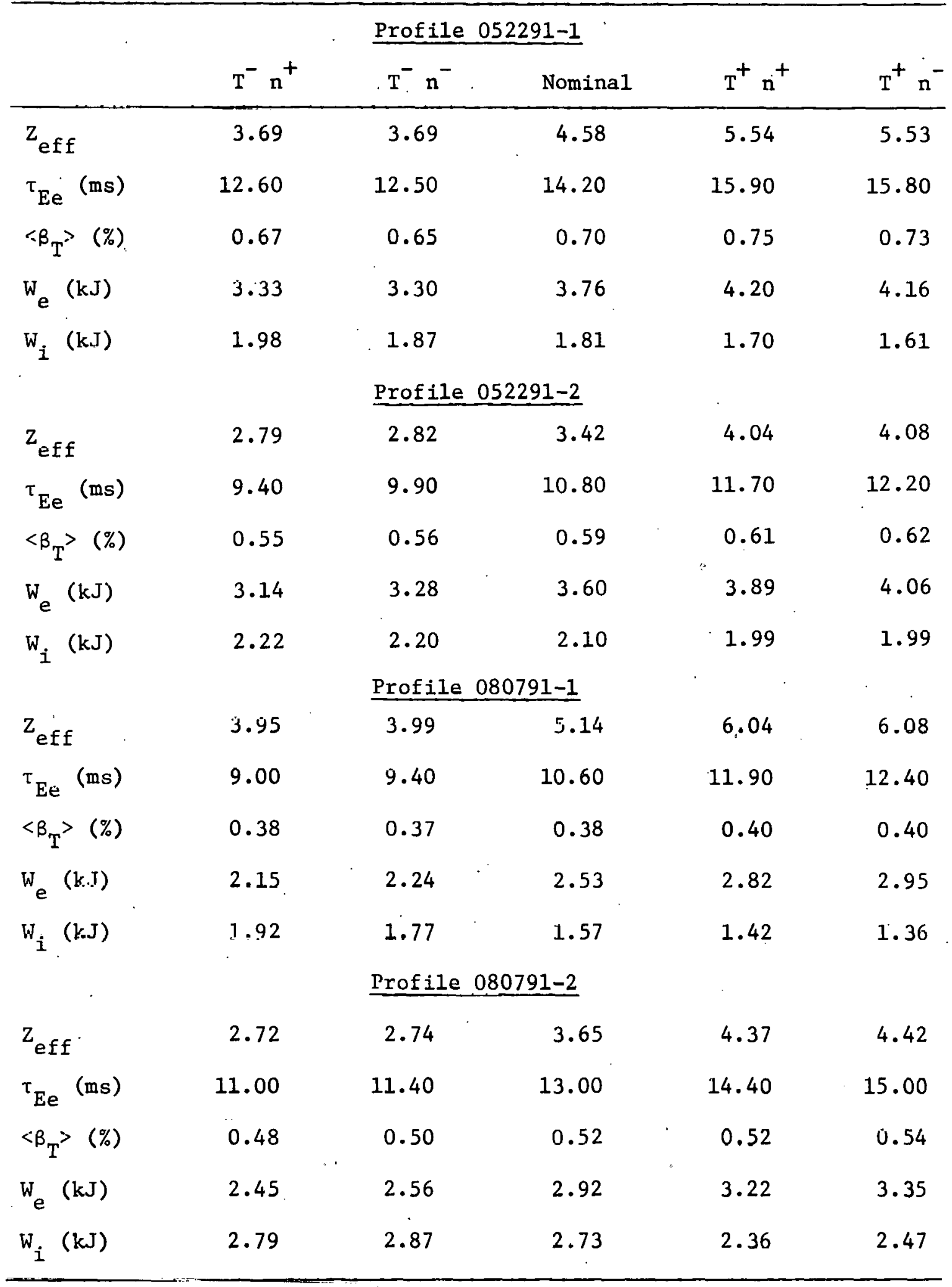


ORNL-DWG 80-2036 FED

POWER FUNCTION FIT: CENTER AT -4.75

$Y=A 1<1-((X-X \theta) / A 2) * *(2 A 3)>* *(2 A 4)+2 \theta$

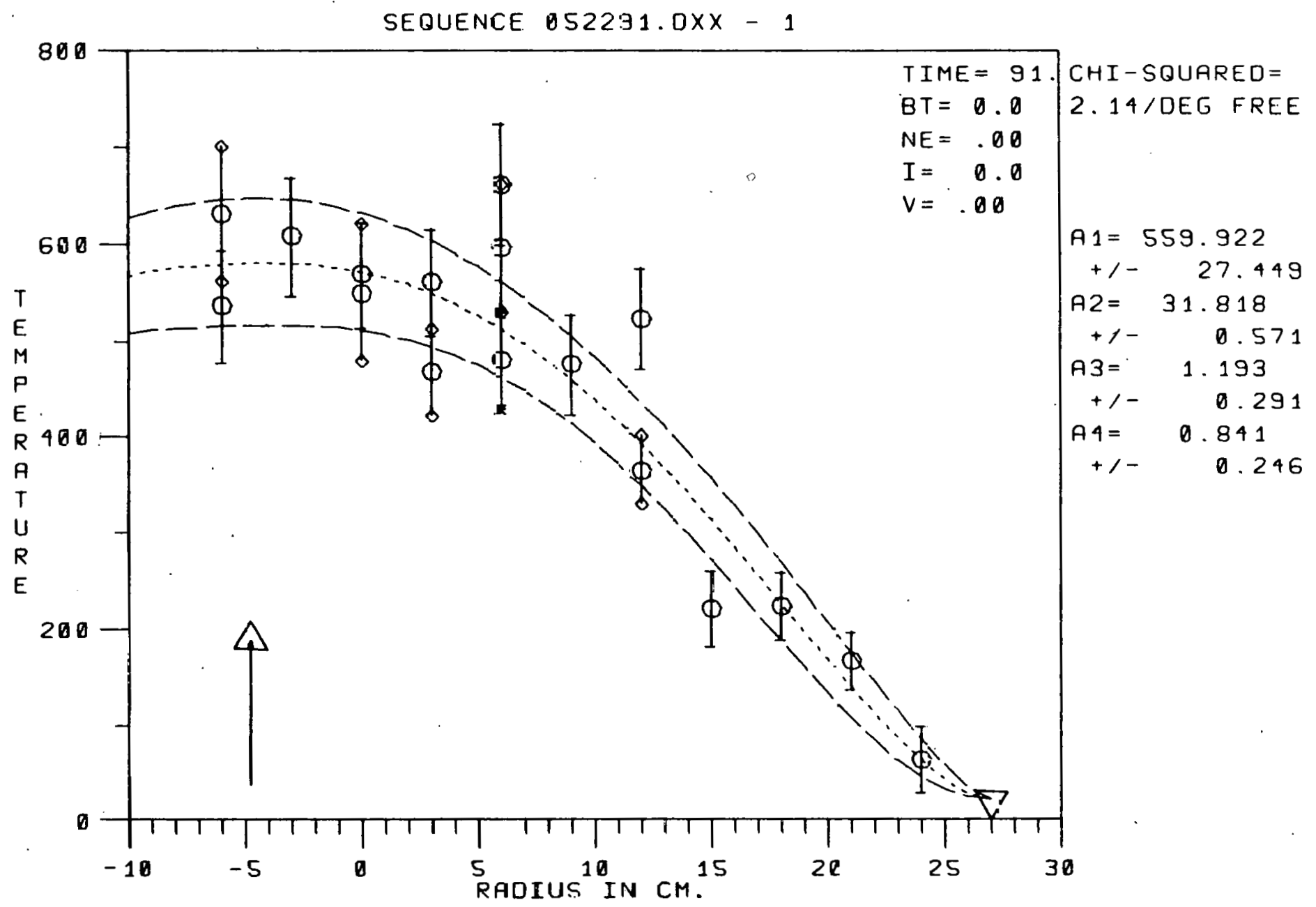

Fig. 1. (a) Typical pcwer furction fit of temperature profile. 
OANL-DWG 80-2037 FED

CUBIC FIT: CENTER AT -4.75

$Y=A 1+A 2(X-X \theta) * * 2+A 3(X-X \theta) * * 3$

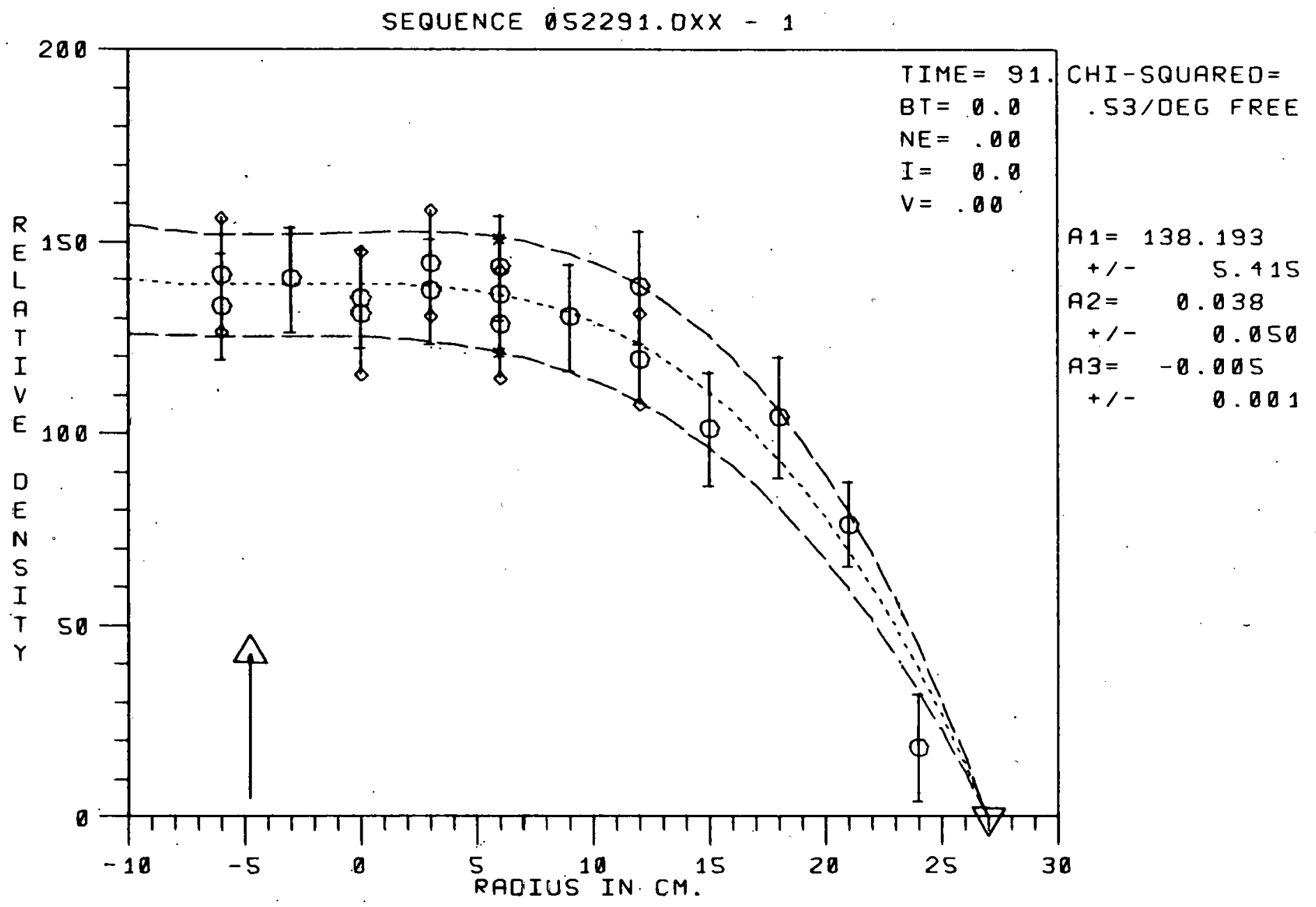

Fig. 1. (b) Typical cubic fit of relative density profile. 
ORNL-DWG $80 \cdot 2038$ FED

FI XEO CENTER SUPER GAUSSIAN

$Y=A 1 * E X P-<((X-X O) / A 2) * * 2>* * A 3+20$.

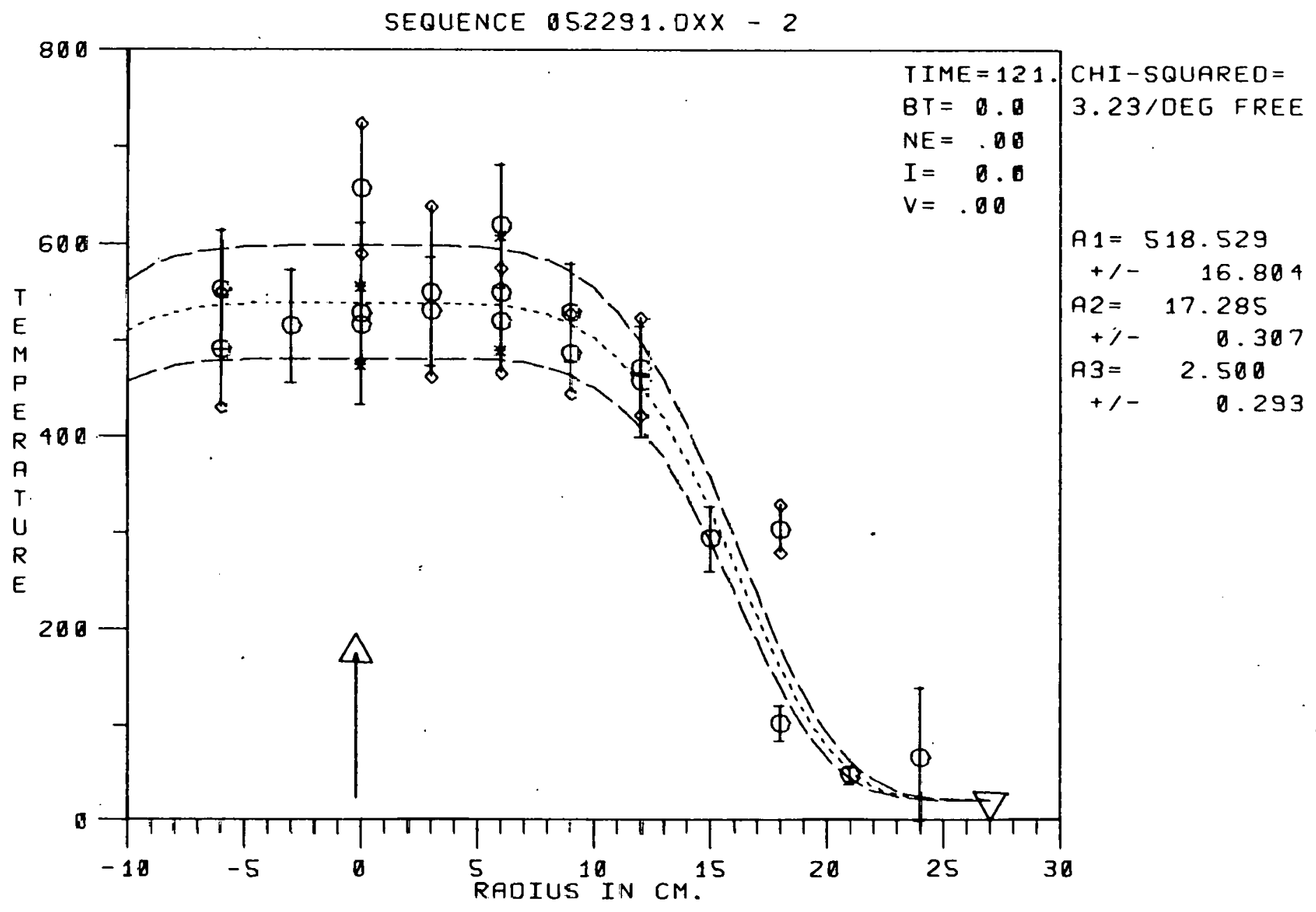

Fig. 2. (a) Typical fixed center super Gaussian fit of tempercture profile. 
ORNL-DWG 80 - 2039

FIXED CENTER SUPER GAUSSIAN

$Y=A 1 * E X P-<((X-X 0) / A 2) * 2>* A 3+0.416$

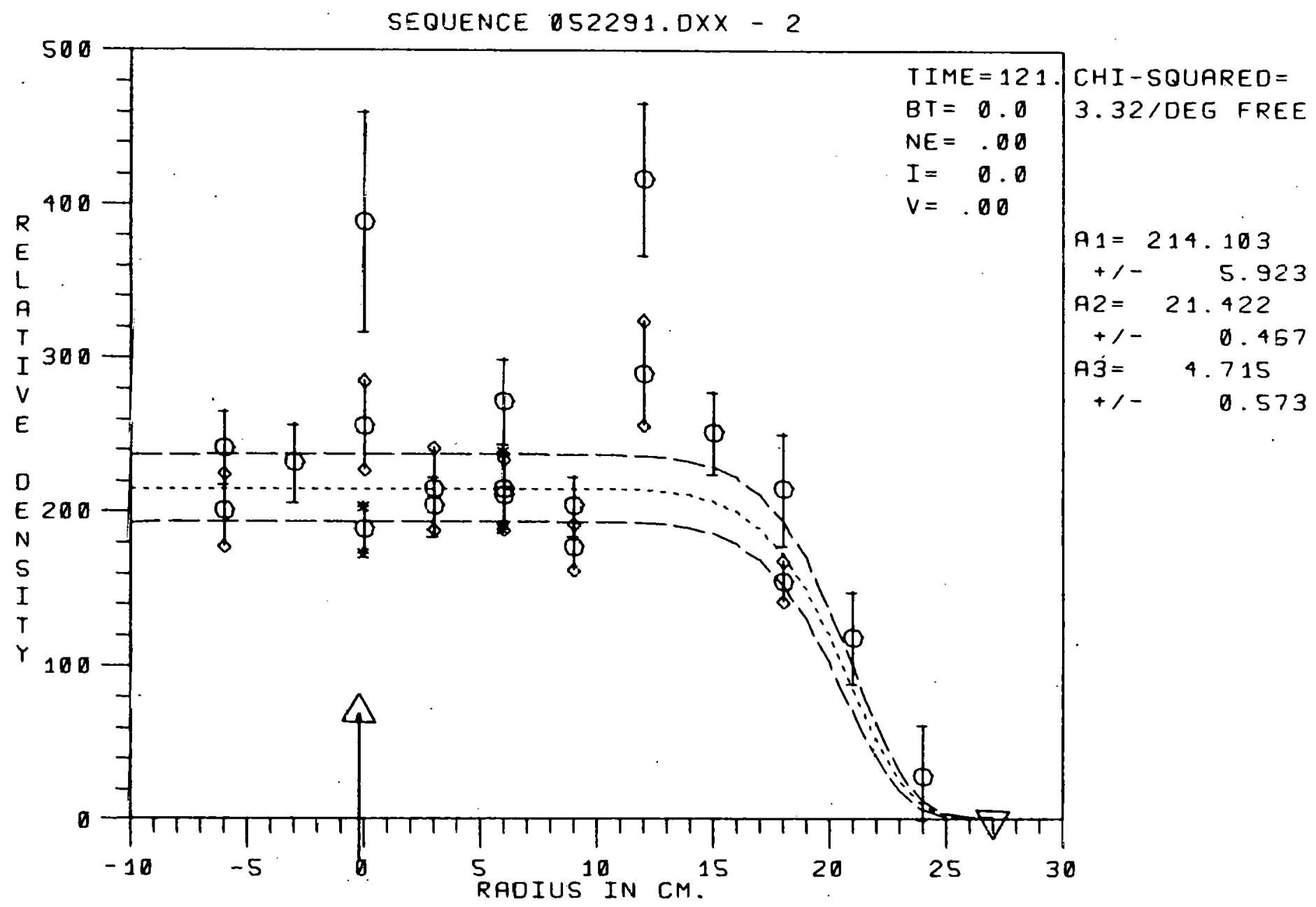

Fig. 2. (b) Typical fixed center super Gaussian fit of relative density profile. 


\section{SUMMARY}

Testing of the Thomson scattering profile analysis package has proven it to be a reliable alternative to the hand fitting of data. The time spent analyzing sequences has been reduced substantially without drastically altering the results. Error analysis has provided estimates of the sensitivity of plasma parameters to the typical uncertainties in Thomson scattering data. Furthermore, the changes in plasma properties due to the conversion to automated fitting fall within this range of uncortainty. Fur the future, the computing packaye may serve as a starliul polne for more thorough calculations. 
APPENDIX A

\section{DETAILED DESCRIPTION OF THE DATA ANALYSIS PACKAGE}

The Thomson scattering data analysis group now has an area of disk on the PDP-10 reserved solely for execution of routines and storage of data related to Thomson scattering. Described here are the purpose and operation of each routine in this area. This is to include the generation of data to the final output of plasma properties from zoRDIC. ${ }^{1}$ Data analysis routines to be referenced in this section include:

(1) LASMIT - transfers profiles from the PDP-8 to the PDP-10 (file extension .DA)

(2) SEQDAT - plots and averages gross plasma conditions at laser firing times (including BT, PC, VX, ENMX, with standard deviations)

(3) PROFIT - parametric fits of profiles

(4) ZIN - prepares output from PROFIT and SEQDAT (files with .ZN extension) into ZORDIC input form; auto/manual entry of data and update capability

(5) PROFIL - plots ZORDIC input profiles (may be data or fits); creates plots suitable for publication

(6) ZORDIC - the primary data analysis code that uses profiles plus gross plasma conditions to generate various plasma properties such as $q, \beta, W$, etc. for both ohmic and beam-injected discharges

(7) ERRFIT - version of PROFIT that fits error bounds on data to produce error envelope

(8) TEST - accepts fitting parameters with uncertainties to produce an error envelope, assuming no correlation between parameters

Table A.1 lists the data file names used in these routines.

1. SE'Q́A'l (Sample output in Appendix D)

SEQDAT is an averaging routine, like PROFIT, that is designed to feed ZORDIC with input through ZIN. In this case, the gross machine characteristics are to be averaged over all shots used in the profile, at the times corresponding to ruby laser pulses. The essential data are 
toroidal field, loop voltage, plasma current, and line-averaged density. For these data, standard deviations are calculated. In addition to averaging the shots in a sequence, some amount of smoothing in time is done via a Gaussian filtering technique. The degree of smoothing is an option available for each parameter.

Table A.1. Data file names

\begin{tabular}{|c|c|}
\hline Example: & $\begin{array}{l}\text { Sequence } \# 2 \text { deuterium } \\
\text { plasma, hydrogen } \\
\text { pellets, no beams }\end{array}$ \\
\hline File name & Purpose \\
\hline $052492 . D A$ & $\begin{array}{l}\text { Profile data points sent to PDP-10 } \\
\text { from PDP-8 }\end{array}$ \\
\hline $052492.2 N 5$ & $\begin{array}{l}\text { SEQDAT output of gross plasma } \\
\text { conditions }\end{array}$ \\
\hline $\begin{array}{l}\text { 052492.ZN1 } \\
\text { through } \\
\text { 052492.ZN4 }\end{array}$ & $\begin{array}{l}\text { PROFIT output of fitted temperature } \\
\text { and density profiles for four laser } \\
\text { pulses }\end{array}$ \\
\hline 052492.DHX & ZORDIC input file created by ZIN \\
\hline $\begin{array}{l}\text { ZO5249.2D1 } \\
\text { through } \\
\text { z05249.2D }\end{array}$ & ZORDIC output files for all four pulses \\
\hline $\begin{array}{l}\text { TIL.D13 } \\
\text { through } \\
\text { TIL.D16 }\end{array}$ & $\begin{array}{l}\text { 2ORDIC output files that are. } \\
\text { immediately printed out and deleted } \\
\text { from the disk (part of TIL.D14 } \\
\text { appears as Appendix G) }\end{array}$ \\
\hline
\end{tabular}

\section{PROFIT (Sample output in Appendix E)}

In PROFIT, both the electron temperature and the relative electron densicy profiles are fitted with smooth, analytic curves (see Fig. B.1). Table A.2 lists the files that make up PROFIT and the subroutines in each file. Before fitting these profiles, the electron kinetic pressure, 
Table A.2. File structure of PROFIT

\begin{tabular}{lllll}
\hline & \multicolumn{4}{c}{ Contents } \\
\hline PROTIT & PLOTN & FITT & FUNCTN & RUN'.MAC \\
\hline PROFIT & PLOT1 & NEWRAP & FUNCL & (assemb1y \\
SETUP & PLOT2 & FITT & FUNC & language \\
MINCHI & PLOT3 & MATINV & & \\
EVALUE & PLOT4 & & & \\
UNVALU & AVPLOT & & & \\
& PLOTCH & & & \\
\hline
\end{tabular}

Brief descriptions

PROFIT

PROFIT main calling routine, all input/output, logical contro1 and decisions

SETUP sets up .ZN files in a format compatible with ZIN

MINCHI controls the actual fitting, determines the function with the best $x^{2}$

EVALUE shifts data from the storage arrays to the working arrays

UNVALU stores the working arrays (YFIT, $B B, A A$ ) into storage arrays (SAVY, SAVA, SAVB)

PLOTN

PLOTl single plot with parameters and standard deviations displayed

PLOT2 overlap plot used by PLOT4 for multiple graphs

PLOT3 establishes the first graph for the multiple graph, for AVPLOT, and for the pressure plot

PLOT4 controller for plotting of multiple graph with $\chi^{2}$

AVPLOT produces average values at each station with uncertainties, calls PLOT3 or PLOT1 depending upon which average is being performed

PLOTCH places the values of $x^{2}$ on PLOT3

FITT

NEWRAP nonlinear least squares fitting routine producing parameter array and covariance matrix; the diagonal of the covariance matrix is the variance array

MATINV inverts matrices and performs the vector operation $\underline{\mathrm{C}}=\underline{\mathrm{A}}^{-1} \cdot \underline{\mathrm{B}}$

FITT. linear least squares fitting routine; functions that can be 1.inearized, such as Ae ${ }^{a x}$, may be fitted with F''l'l', if the proper calculations are performed in FUNCL 
Table A.2 (continued)

Brief descriptions

FUNCTN

FUNCL sets up the fits by defining the function and giving initial guesses to NEWRAP; FUNCL calls either FITT or NEWRAP and evaluates the fit after parameters are passed

FUNC a subroutine used only by NEWRAP; it computes values of the derivatives of $\chi^{2}$ with respect to the parameters (i.e., the Taylor expansion coefficients)

RUN.MAC is used to begin execution of system program TKFVER to output plots onto the PDP-10 Versatec 


$$
\mathrm{nT}=\mathrm{a}_{1}\left(\mathrm{x}-\mathrm{a}_{2}\right)^{2},
$$

is fitted with a symmetric parabola in order to fix the plasma center. The fits will all be forced to have zero first derivatives at the plasma center. 'In this way the peak in the temperature, the density, and the pressure will all coincide at each instant of time.

After fixing the center, the user selects a fit from one of four curves that are currently being displayed. These functions are:

(1) Gaussian

(2) cubic

(3) "super Gaussian"

(4) "power function" $a_{1} \exp -\left(\frac{x-x o}{a_{2}}\right)^{2}$

$$
a_{1}(x-x o)^{3}+a_{2}(x-x o)^{2}+a_{3}
$$

$a_{1} \exp -\left(\frac{x-x o}{a_{2}}\right)^{2 a_{3}}$,

$a_{1}\left[1-\left(\frac{x-x o}{a_{2}}\right)^{2 a_{3}}\right]^{2 a_{4}}$,

where xo is the plasma center. These functions were chosen to give a maximum of flexibility in fitting anticipated shapes.

The reduced $x^{2}$ ( $\chi^{2}$ per degree of freedom) is calculated in each case to aid, or even control, the selection. At this point, the chosen function is evaluated at $1-\mathrm{cm}$ increments, and a $2 I N$-input file is created that contains these values as well as the parameters of the fit. The chosen function is then displayed to the user for closer inspection. Some of the specific features of PROFIT derived from this procedure are:

(1) The determination of parameters for the fits is done in either FITT or NEWRAP, using the standard technique of weighted least squares (see Fig. B.2). Except for the cubis polynomial fit, a nonlinear least squares routine is used. The definition of $x^{2}$ is 


$$
x^{2} \equiv \sum_{i=1}^{n} \frac{\left[y_{i}-f\left(x_{i} ; \underline{\alpha}\right)\right]^{2}}{\sigma^{2}},
$$

where $\underline{\alpha}$ is the parameter array. $\chi^{2}$ is Taylor expanded with respect to the parameter array, and successive iterations serve to locate the local minimum. Good initial guesses are required, particularly as the number of parameters goes up and $\chi^{2}$ becomes considerably more structurcd. In order to assist the power function, a crude grid search is performed Initially to locate the global minimum. In the case of the cubic, a linear least squares routine solves exactly for the minimum $x^{2}$ with a single matrix inversion.

(2) Due to the modular structure of the subroutines FUNCL and FUNC, other functions not appearing above may easily be added without upsetting any of the logic or program flow. There is no interplay between the modules in FUNC and FUNCL. Additions must also be made in SETUP and in the plotting routines to properly encode the functional form.

(3) AVPLOT can be used to replot any graph with only one ordinate for each abscissa. The ordinate is a weighted mean defined by

$$
\bar{y}=\frac{\sum \frac{y_{i}}{\sigma^{2}}}{\sum \sigma_{i}^{2}},
$$

and the standard deviation is reduced by $\sqrt{n}$

$$
\bar{u}=\sum_{\sqrt{n}}^{1} \sum \sigma_{i}
$$

(4) Some constraints based on intuition and some physics have been added to the fits. Symmetry about the center is required, except for the cubic, which is penalized in the calculation of a reduced $x^{2}$ by having a degree of freedom subtracted for every point inside of center. Although real plasmas need not (indeed are not) be 
symmetric, since data is taken between $-6 \mathrm{~cm} \geqslant x \geqslant 24 \mathrm{~cm}$, insufficient data is present on the inside of the plasma to allow arbitrary fittings.

Also, the limiter point at $+27 \mathrm{~cm}$ is forced to $\mathrm{T}=20 \mathrm{eV}$ and $\mathrm{n}=0^{+}\left(\mathrm{n}_{\max } / 1000\right)$. Placing a large weight $( \pm 10 \%)$ on the limiter ensures that the curves pass very close to these predetermined values. The effect on. the remainder of the fit can be significant in some cases. Especially when the plasma is shifted out, this condition may lower the fit below the data points at the center.

(5) There are two primary weaknesses associated with our current method. The first is caused by forcing the limiter. The second is slightly less well-defined. In some cases, it appears that the computer misses points due to limited degrees of freedom (between 2 and 4). For instance, a hollow profile is not possible except for the cubic, and even then it shows resistance. In these cases where the data are structured, the individual weights on the data points become quite important, because the computer will sooner miss one point than drastically alter its shape. Of course, in some cases the fit is bad simply because the data are spread and/or the errors are unreasonable. In these cases, even a hand-drawn fit would not be adequate.

\section{3. $\mathrm{ZIN}$}

ZIN is used to manipulate files and accept data in order to produce a ZORDIC input file (see Fig. B.3). The flles created by both PROFIT and SEQDAT are used. ZIN has the added features of optional manual entry of data and the capability of updating files. Manual interactive entry is always the default when no. ZN files can be found. Updating of profiles can be done in either mode, manual entry or reading PROFIT output files. However, updating of gross plasma conditions is currently available only through text editing of the ZORDIC input file. 
4. PROFIL (Sample output in Appendix F)

PROFIL does not manipulate files or do calculations, but rather it produces graphs in an aesthetic and concise format. It will have the capability of viewing data either before or after the data have been fitted.

5. ZORDIC (Sample output in Appendix G)

ZORDIC is the primary set of calculations done on the experimental data to yield extensive information about the plasma. This program has not been modified.

6. TEST

TEST is a display and file writing routine very similar to PROFIT, except that fits are not done in TEST. This routine accepts nominal values of the parameters for the best fit and a standard deviation for each. It then plots the envelope of uncertainty about the best fit and writes a file containing the values of temperature and density that correspond to the envelope limits.

These new profiles can be used in ZORDIC to estimate uncertainties on the parameters calculated in ZORDIC. As discussed earlier, these represent an upper bound assuming no correlation between parameters.

\section{ERRFIT}

ERRFIT is a modified version of PROFIT that fits the data, and in addition fits the data plus and minus the error bars.

\section{REFERENCE}

1. D. L. Shaeffer and M. Murakami (Uak Kidge National Laboratory), private communication, September 30, 1976. 
APPENDIX B

FLOW CHARTS OF PROFIT, ZIN, NEWRAP

Flow charts for the data analysis routines PROFIT, ZIN, and NEWRAP are shown in Figs. B.1, B.2, and B.3, respectively. 
PROFIT FLOW CHART

ORNL-DWG 793031 FED

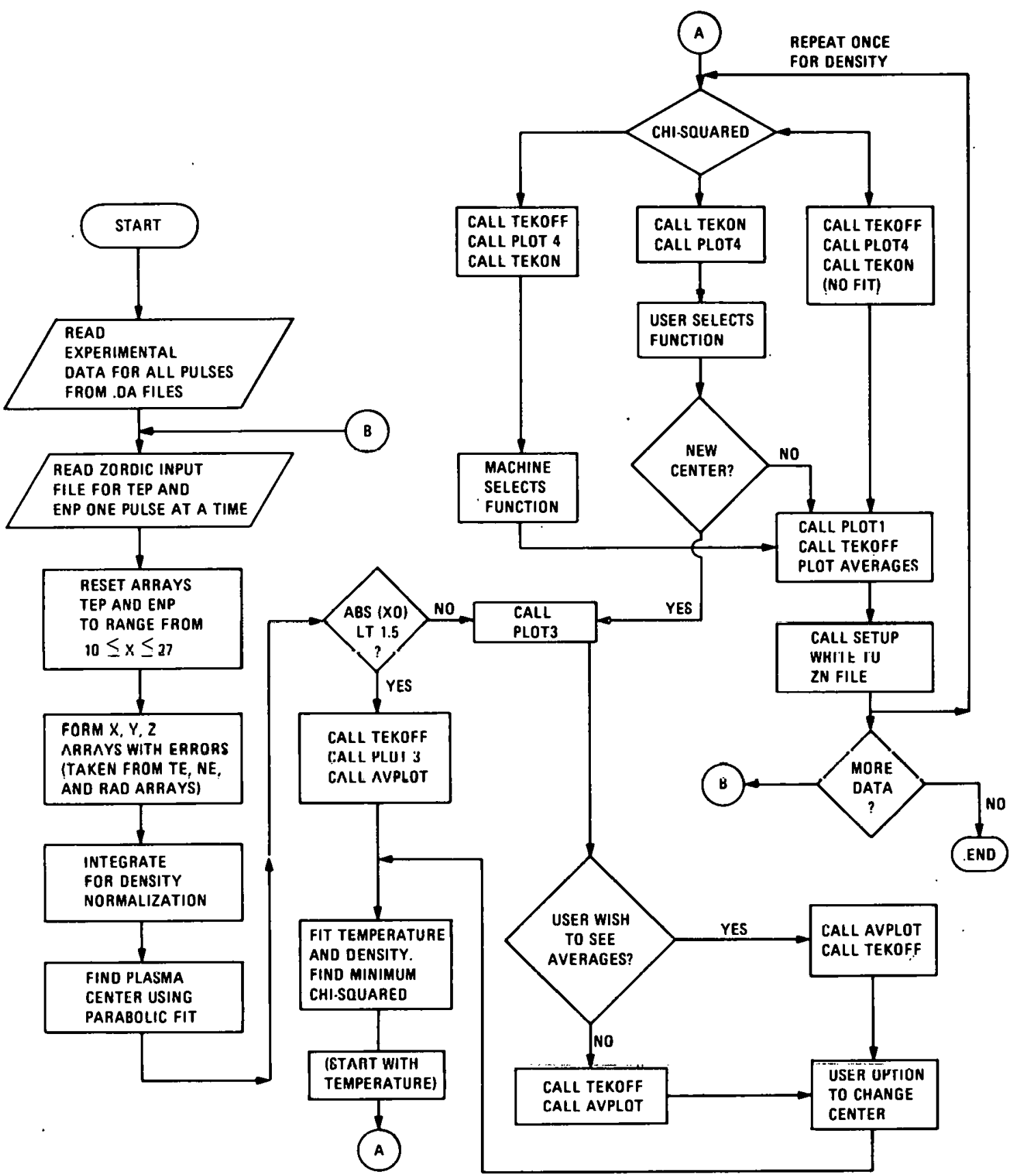

Fig. B.1. PROFIT flow chart. 
ORNL-OWG $79-3032$ FED

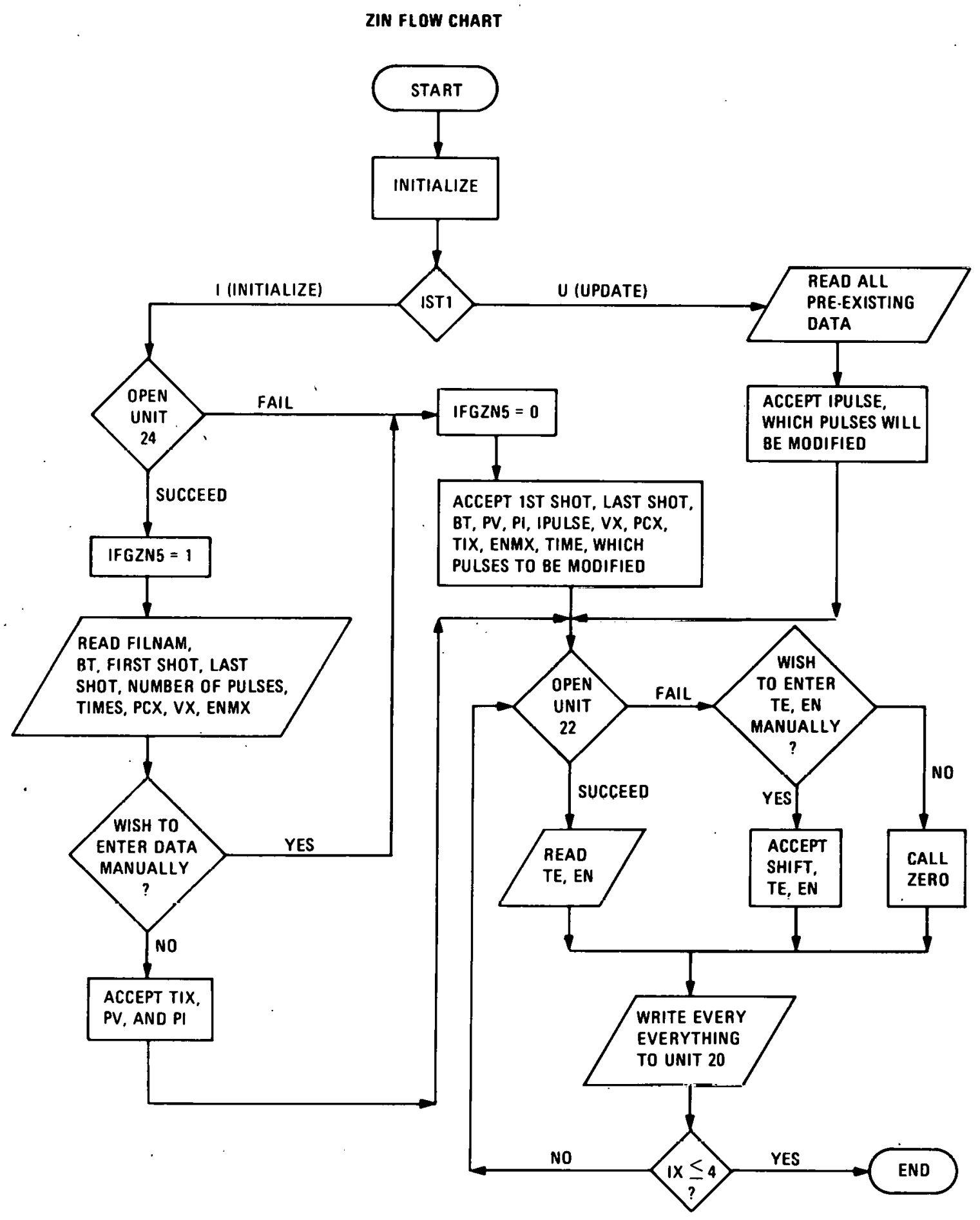

Fig. B.2. ZIN flow chart. 
ORNL-OWG 79-3030 FED

NEWRAP FLOW CHART

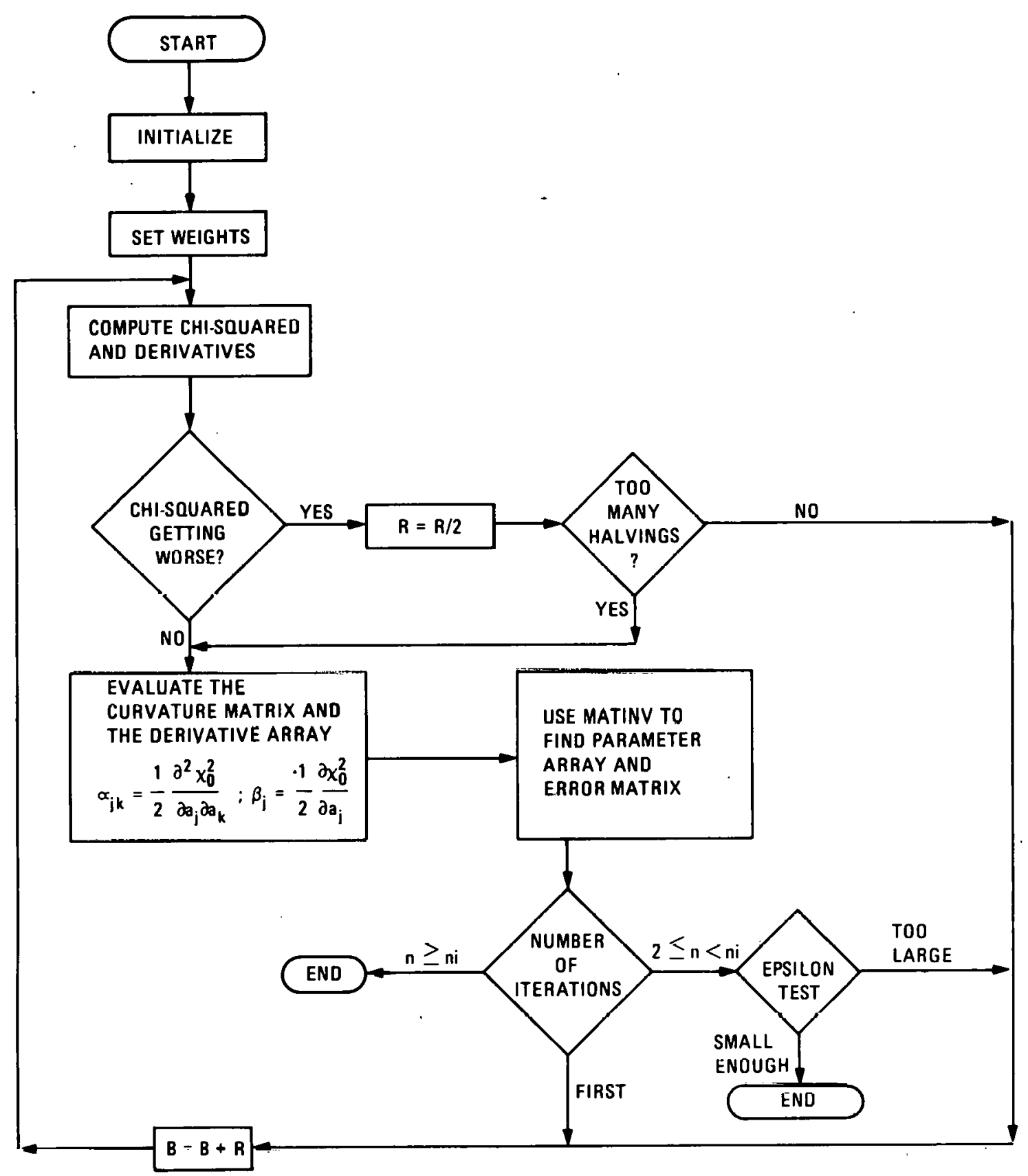

Fig. B.3. NEWRAP flow chart. 
APPENDIX C

COMPARISON PROFILES

Hand-fit vs computer-fit profiles for Profile 052291 are compared in Figs. C.1 and C.2. 
POWER FUNCTION FIT: CENTER AT -4.75 $Y=A 1<1-(C X-X 0 ; / A 2) * *(2 A 3)>* *(2 A 4)+20$

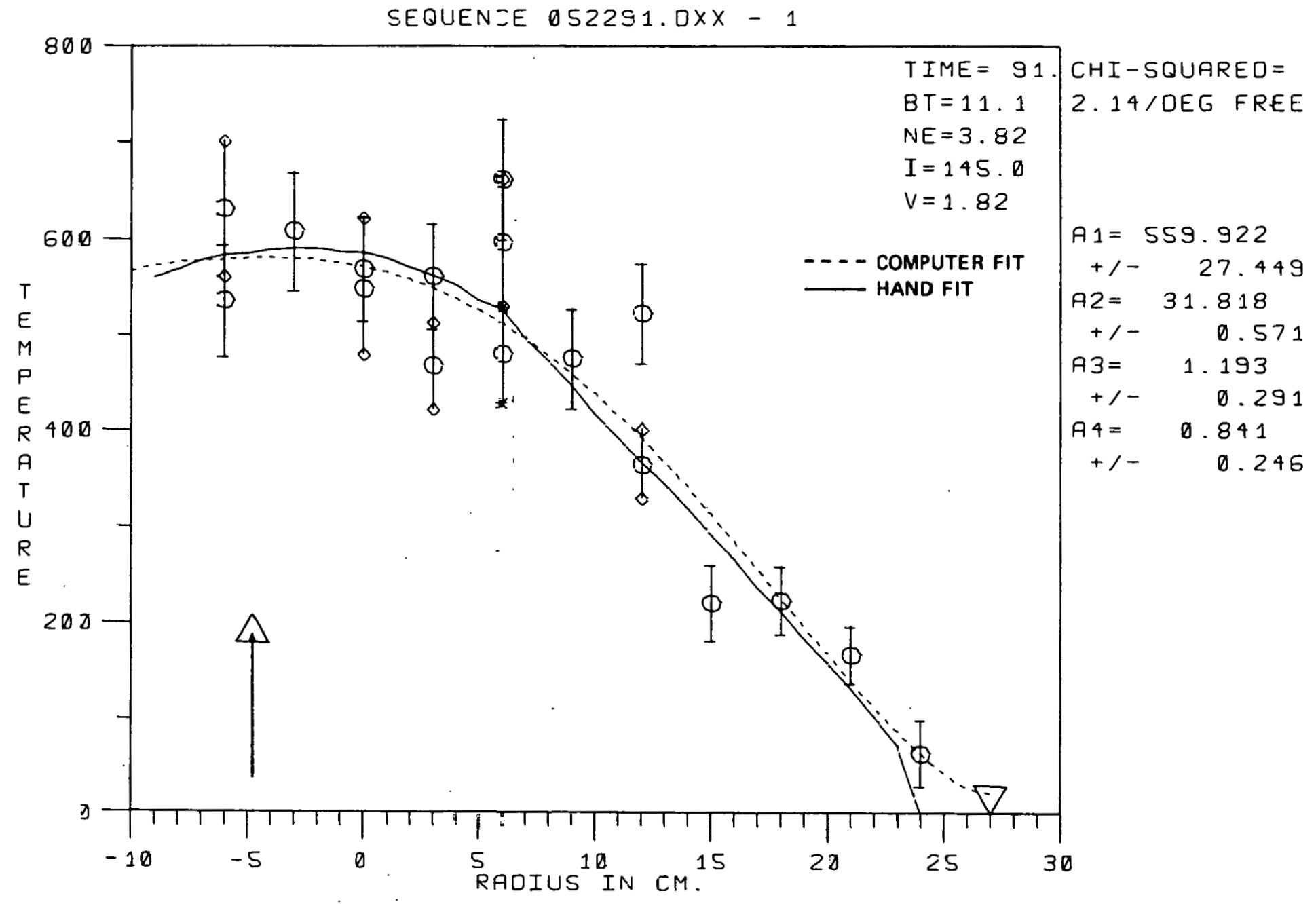

Fig. C.1. (a) Power function fits of temperature profile. 
CUBIC FIT: CENTER AT -4.75

$Y=A 1+A 2(X-X \emptyset) * 2+A 3(X-X 0) * 3$

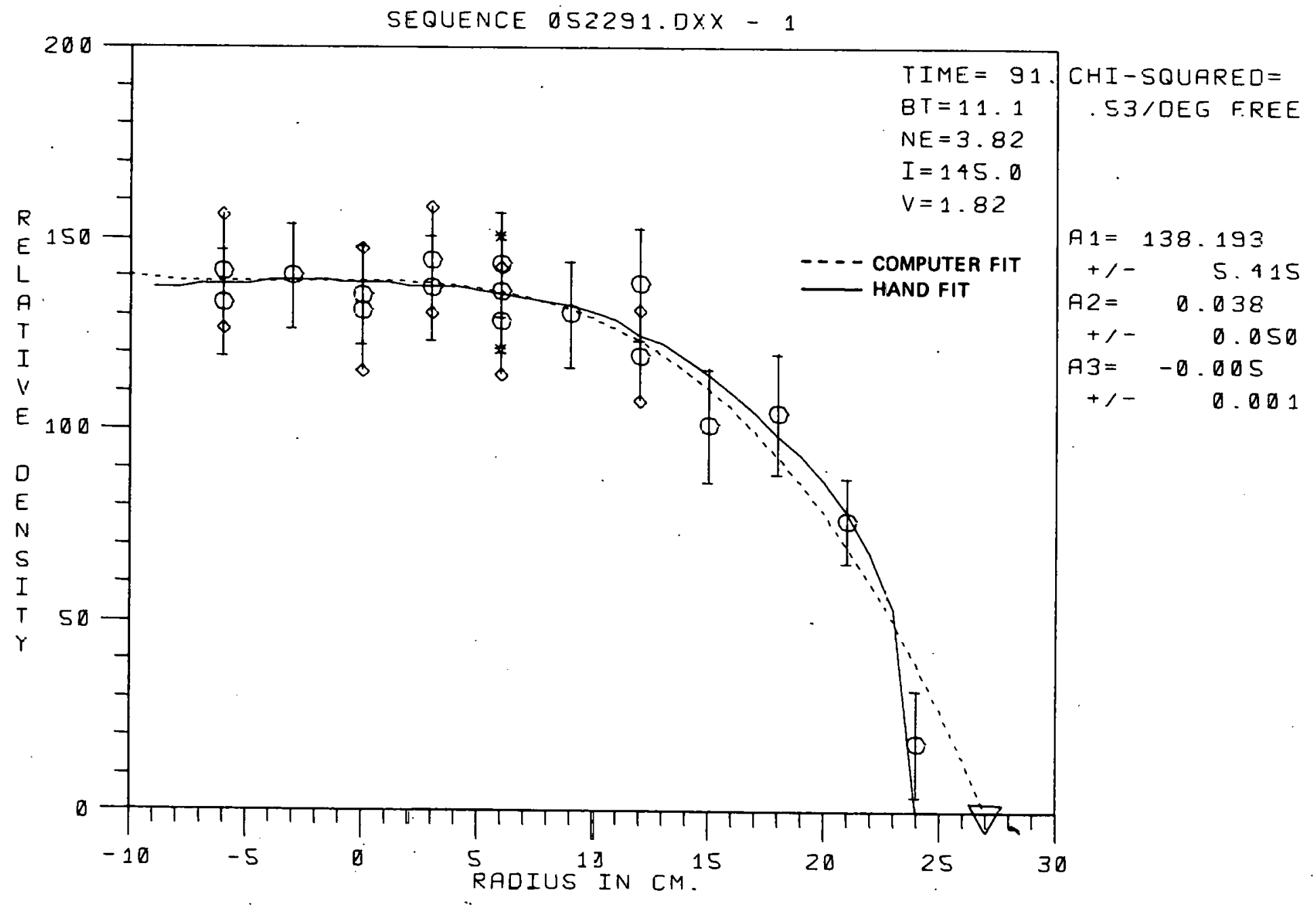

Fig. C.1. (b) Cubic fits of relative density profile. 
POWER FUNCTION FIT : CENTER AT -0.24 $Y=A 1<1-((X-X \theta) / A 2) *(2 A 3)>* *(2 A 4)+20$

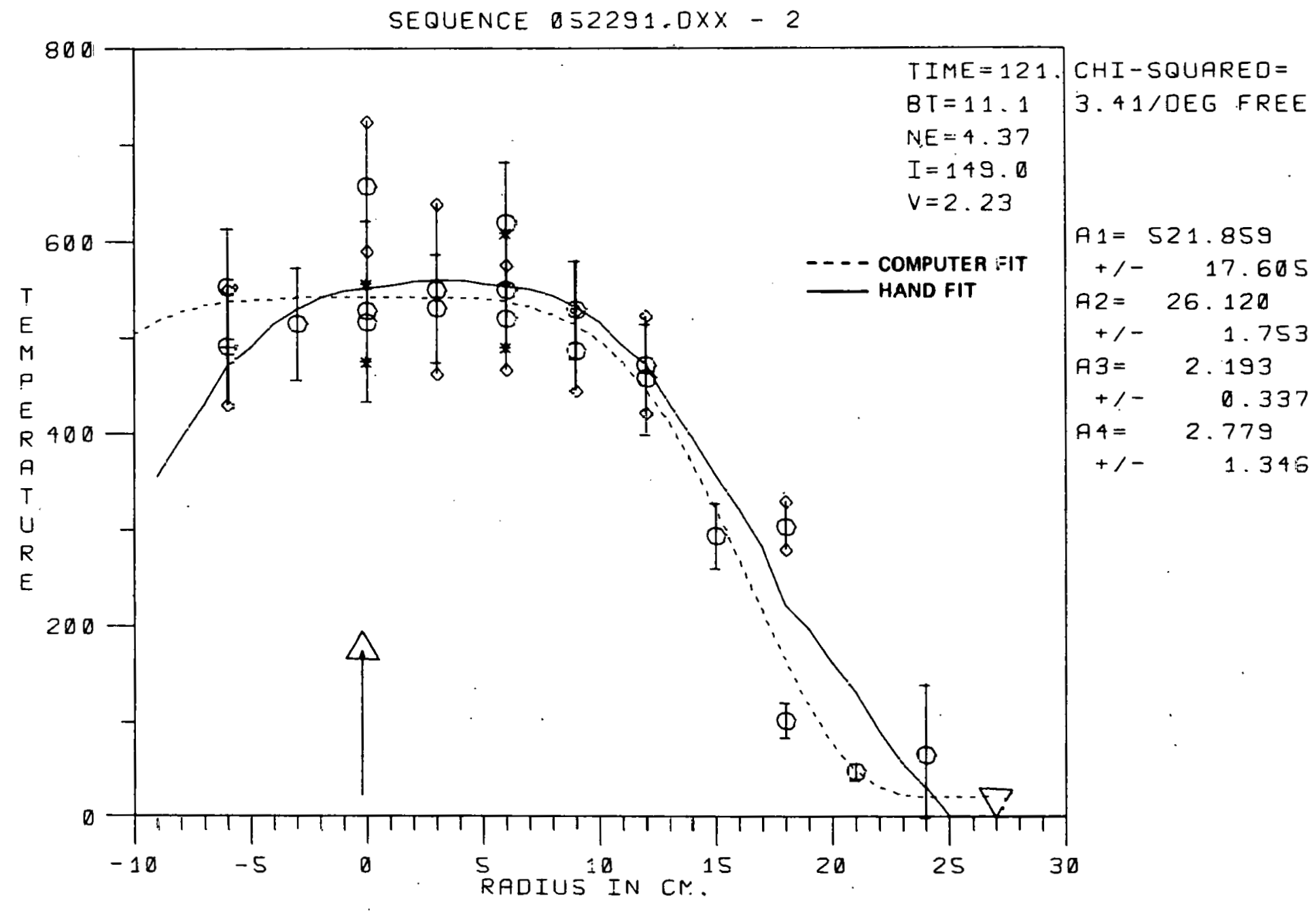

Fig. C.2. (a) Power functicn fits of temperature prafile. 
FIXED CENTER SUPER GAUSSIAN

$Y=A 1 * E X P-<((X-X 0) / A 2) * 2>* * 3+0.416$

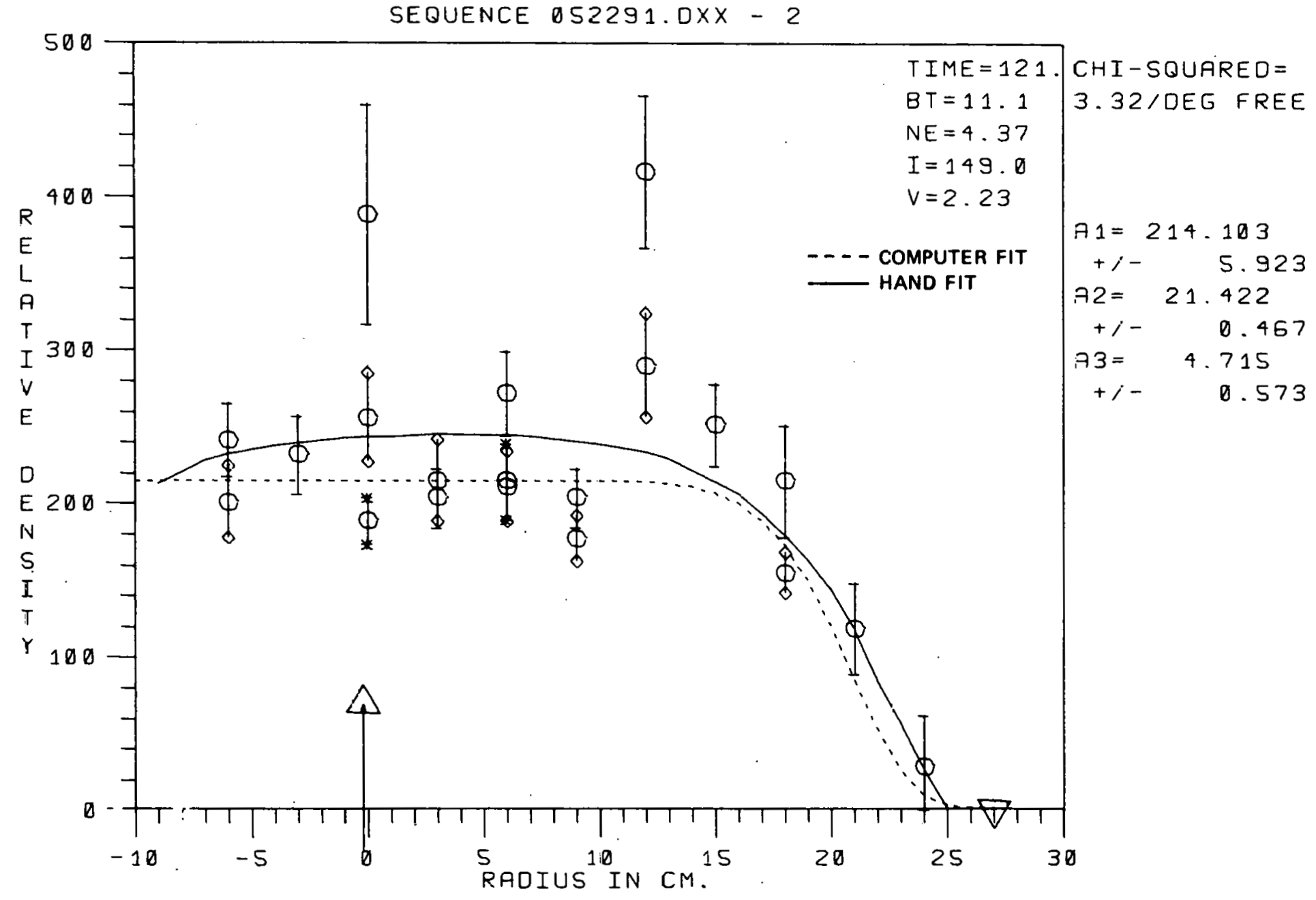

Fig. C.2. (b) Fixed center super Gaussian fits of relative density profile. 


\section{THIS PAGE WAS INTENTIONALLY LEFT BLANK}


APPENDIX D

\section{SEQDAT SAMPLE OUTPUT}

Sample output from SEQDAT is shown for Profile 052291 in Figs. D.1-D.5. 
ORNL-DWG $79 \cdot 3181$ FED
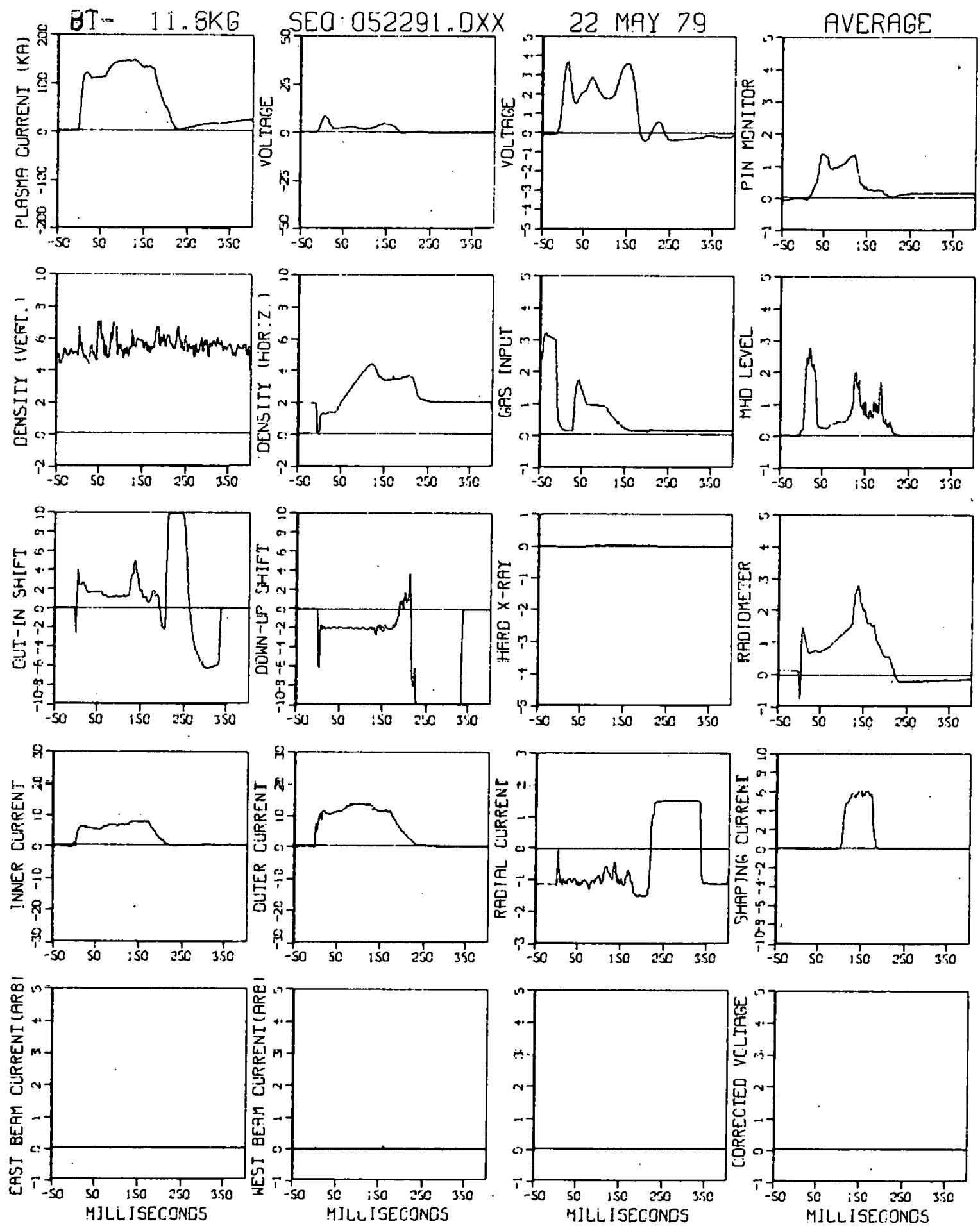

Fig. D.1. Sample output from SEQDAT showing plots of averaged plasma conditions. 
ORNL-DWG 79-3182 FED

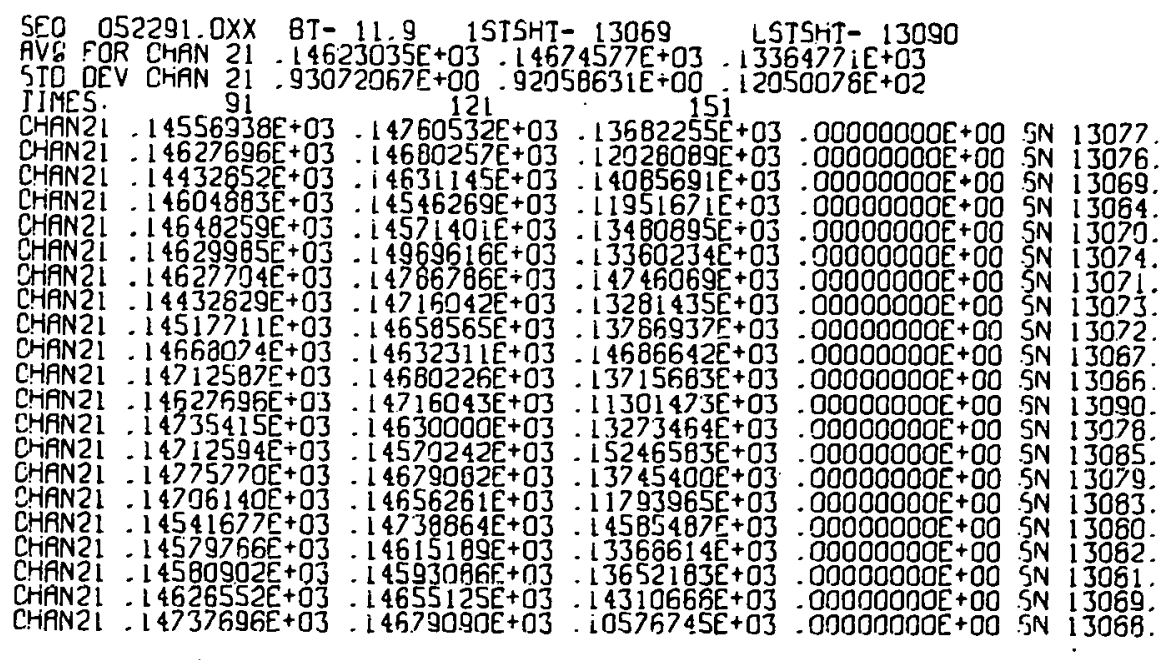

PLASMA CURRENT

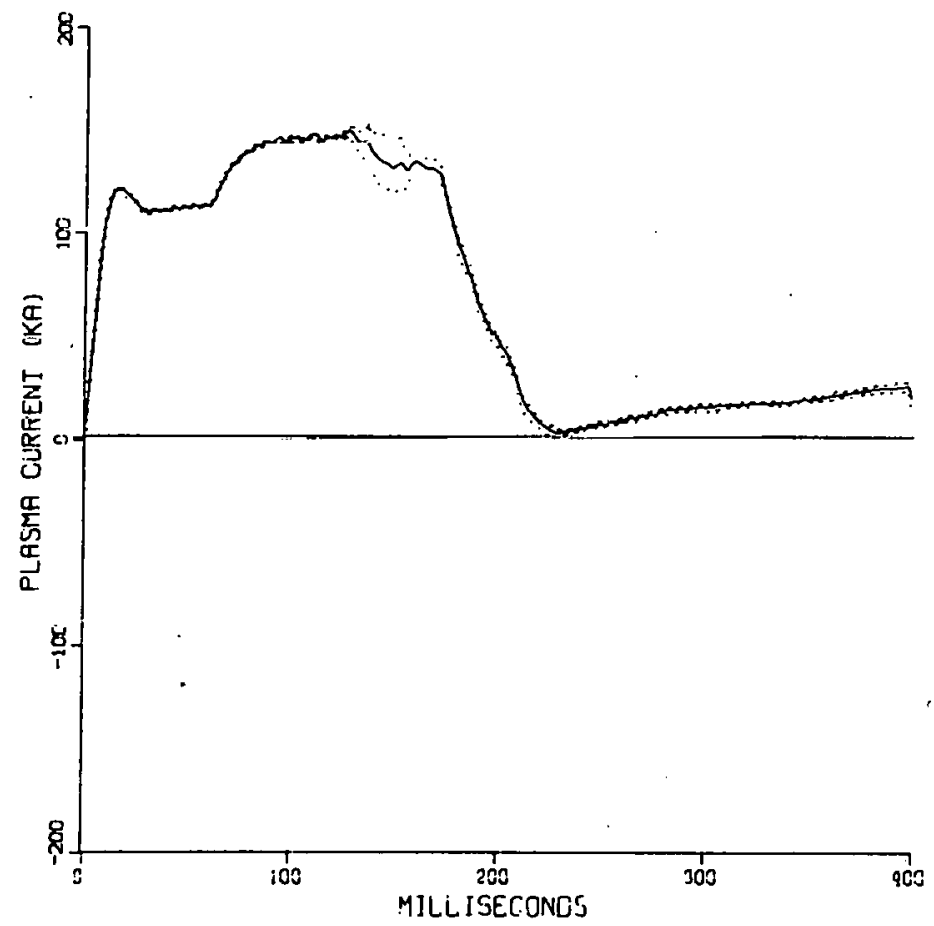

F1g. D.2. Sample plot of averaged plasma current. 
ORNL-DWG 79-3183 FED

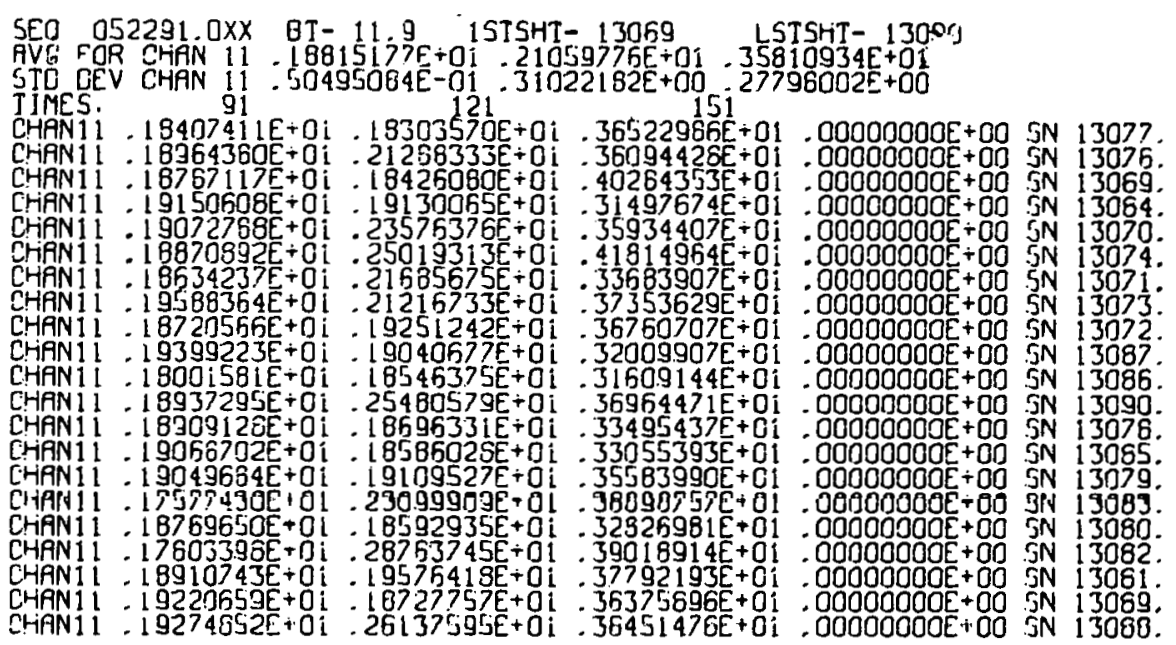

LÓOP VOLTAGE.

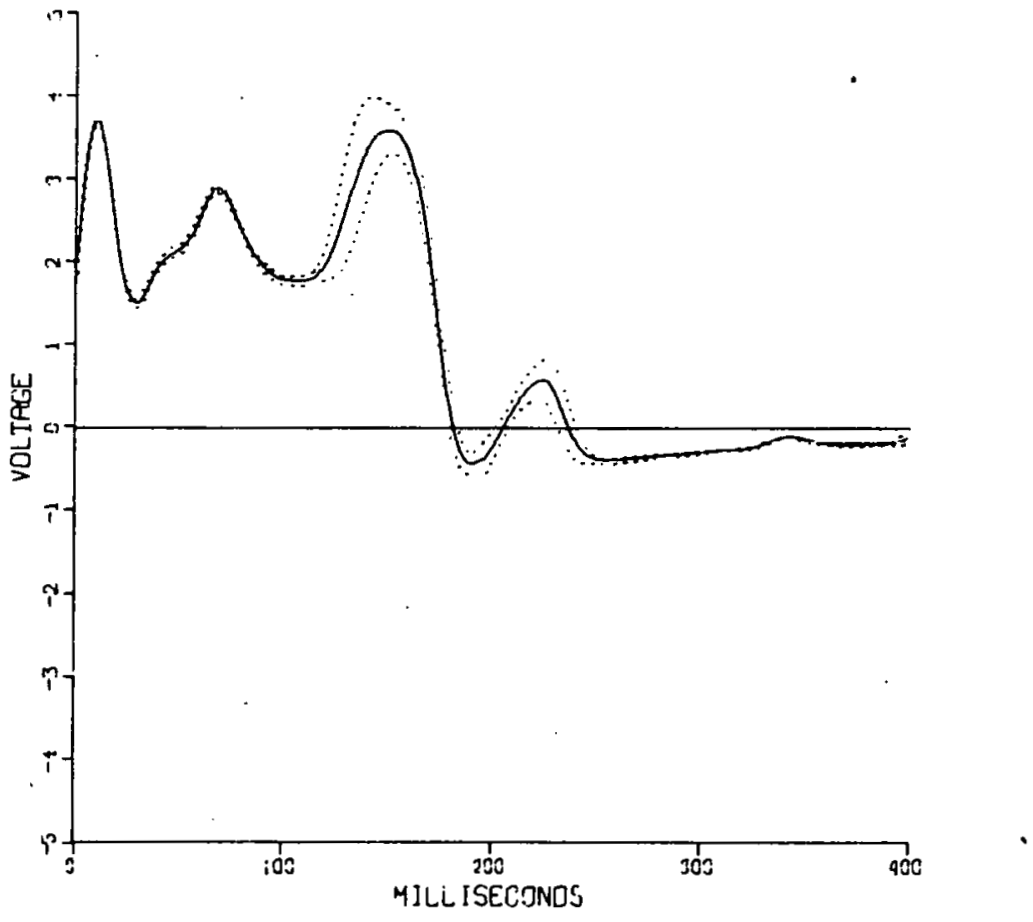

Fig. D.3. Sample plot of averaged loop voltage. 

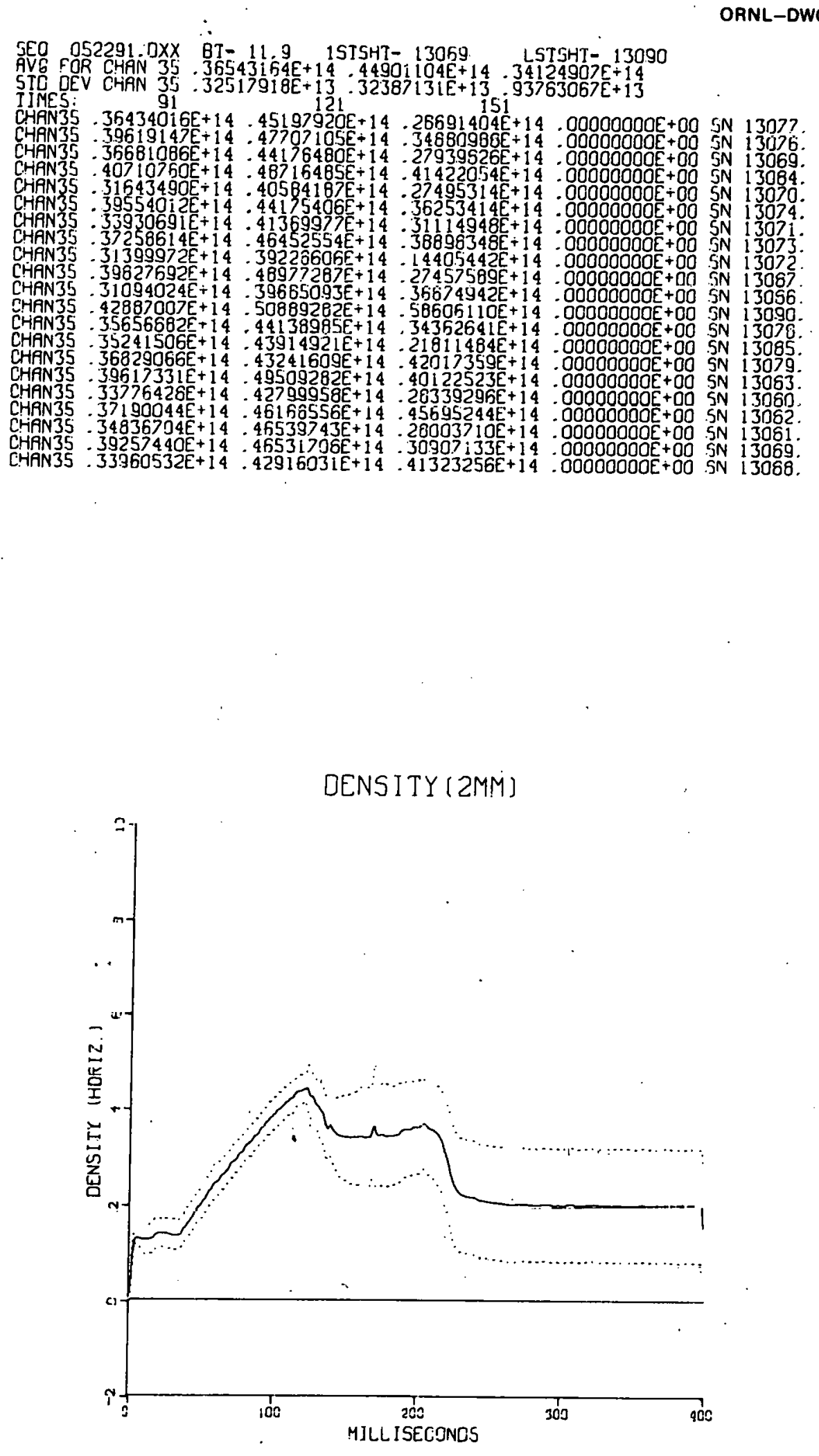

Fig. D.4. Sample plot of averaged density. 
ORNL-DWG 79-3185 FED

SEU DS2291.OXX BT- 1199 1STSHT- 13069 LSTSHT- 13090

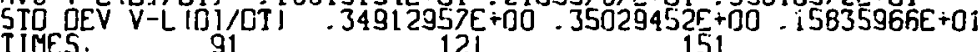

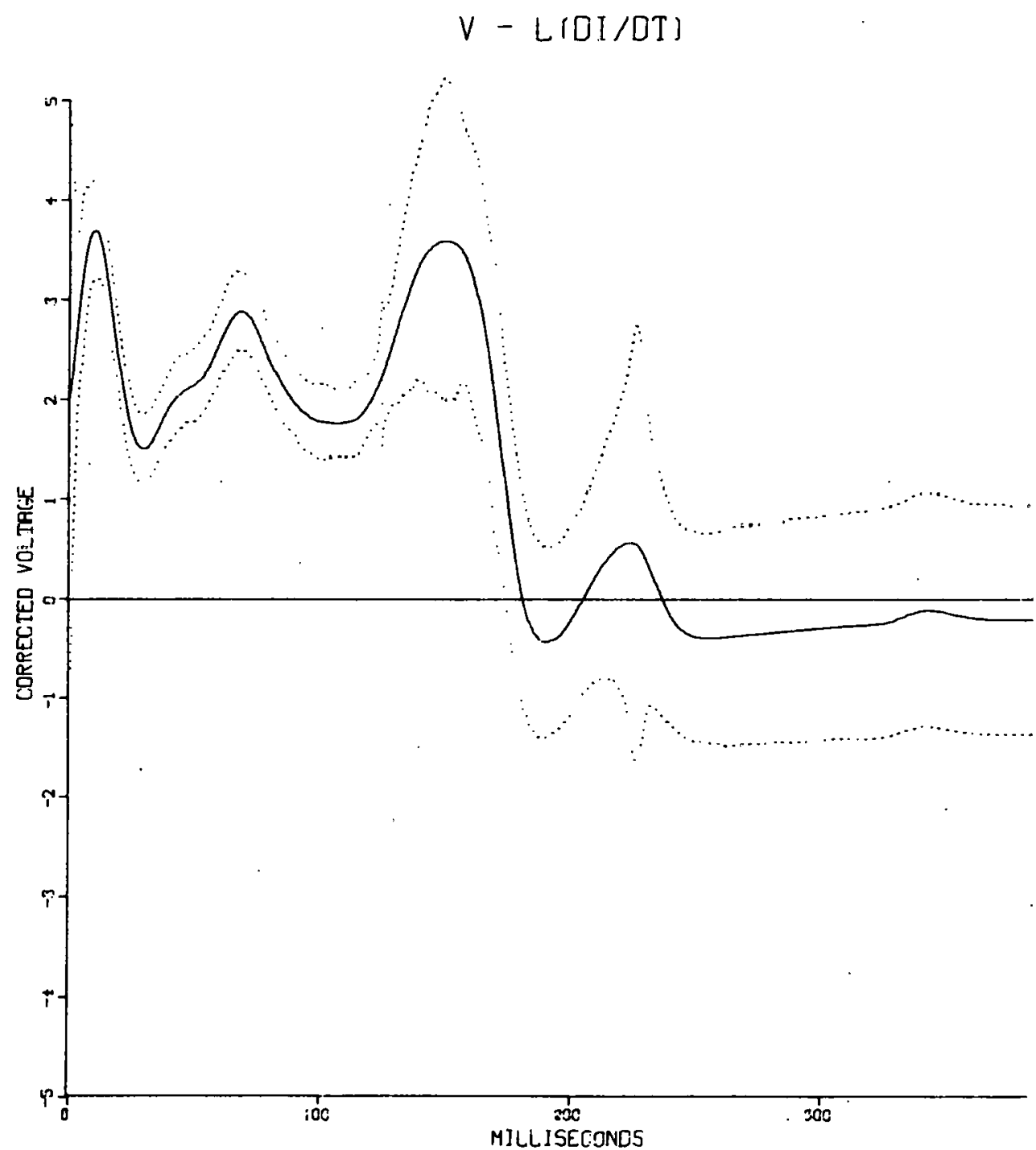

Fig. D.5. Sample plot of averaged corrected voltage. 
APPENDIX E

PROFIT SAMPLE OUTPUT

Sample output from PROFIT is shown for Prof1le 052291 in Figs.'E.1-E.5. 


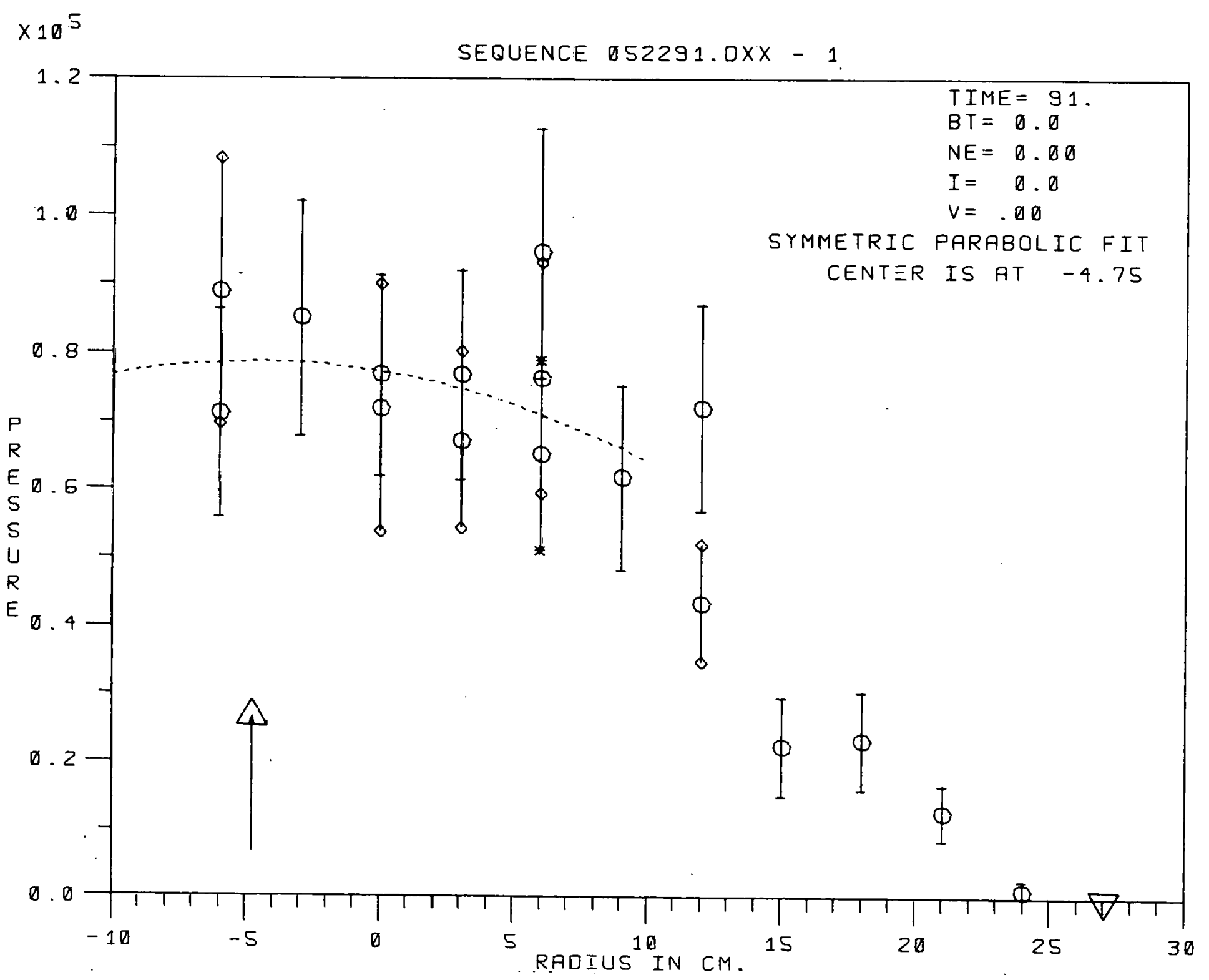

Fig. E.1. Sample output from PROFIT showing symmetric parabolic fit of pressure profile. 
ORNL-DWG $79 \cdot 3190$

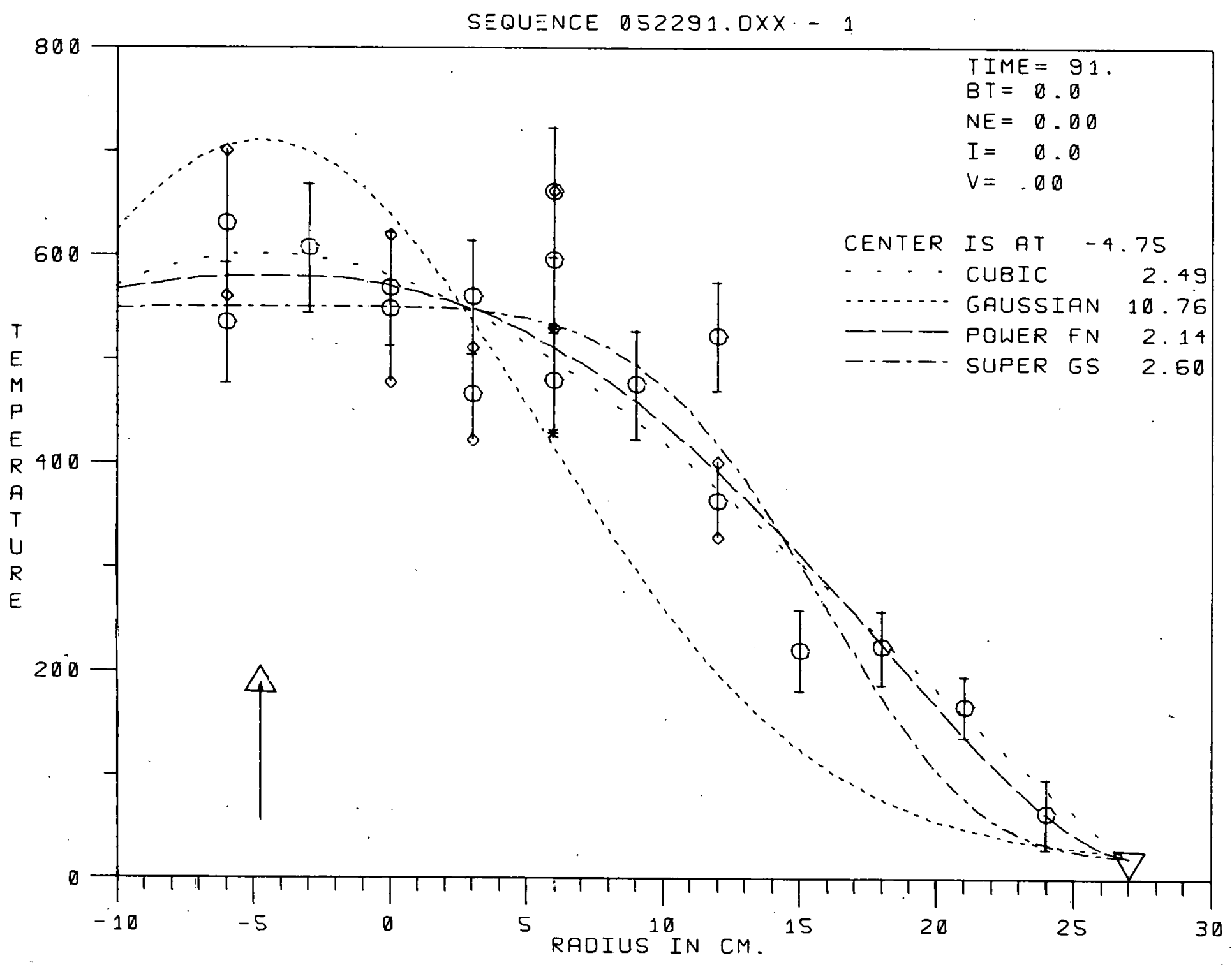

Fig. E.2. Sample output from PROFIT showing four temperature curves. 

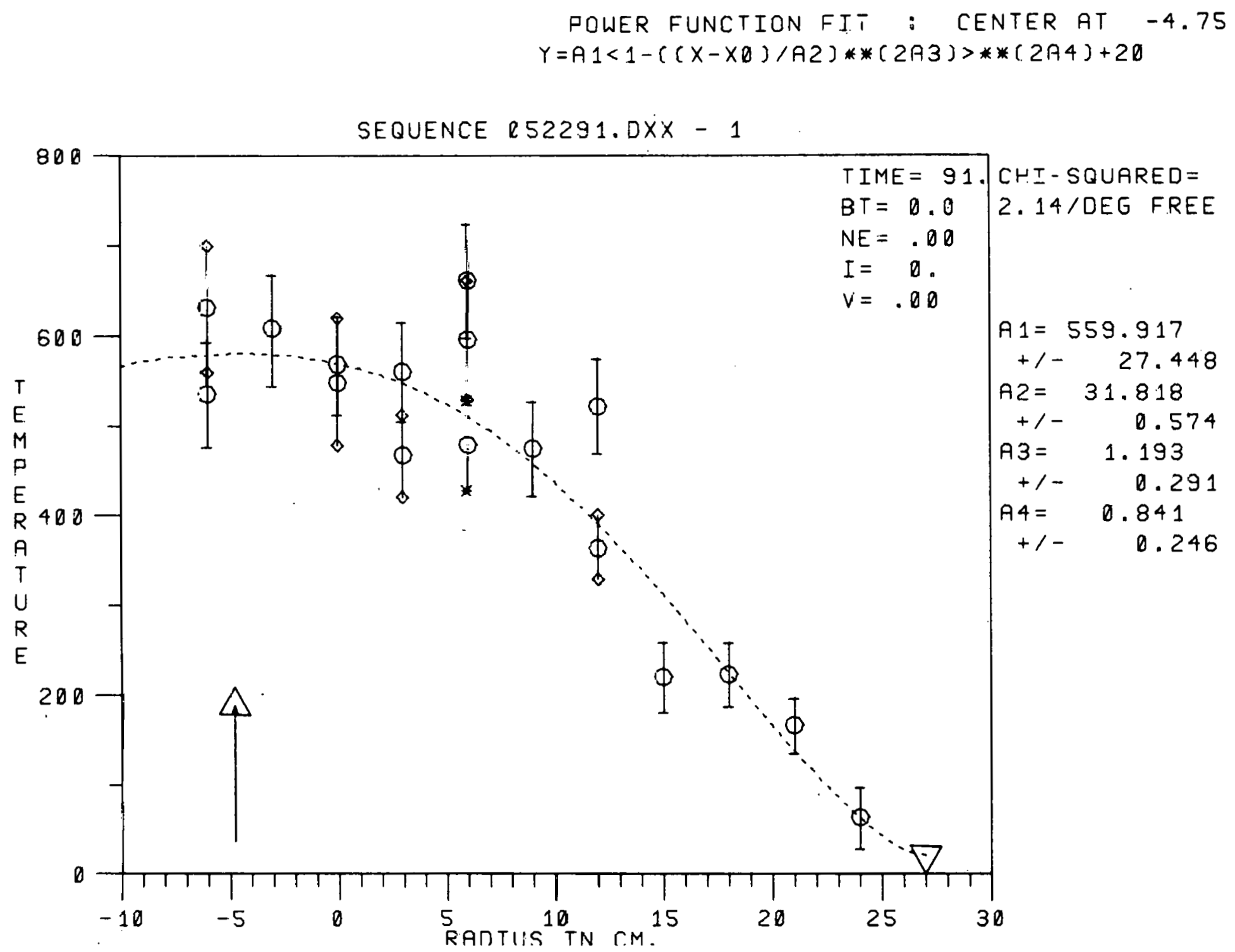

Fig. E.3. Sample output from PROFIT showing a power function fit of the temperature prcfile. 
ORNL-DWG 79.3193 FED

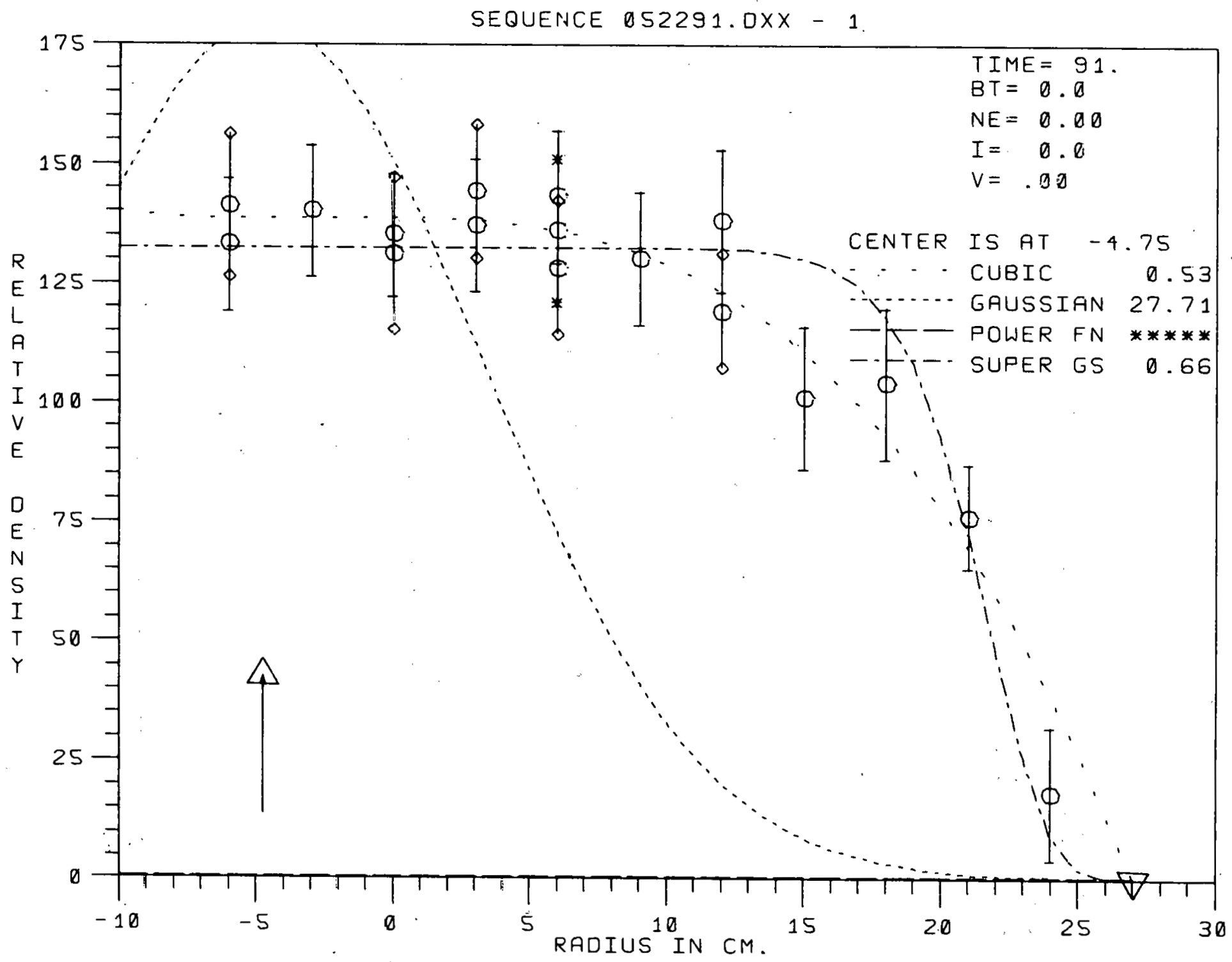

Fig. E.4. Sample output from PROFIT showing four relative density curves. 


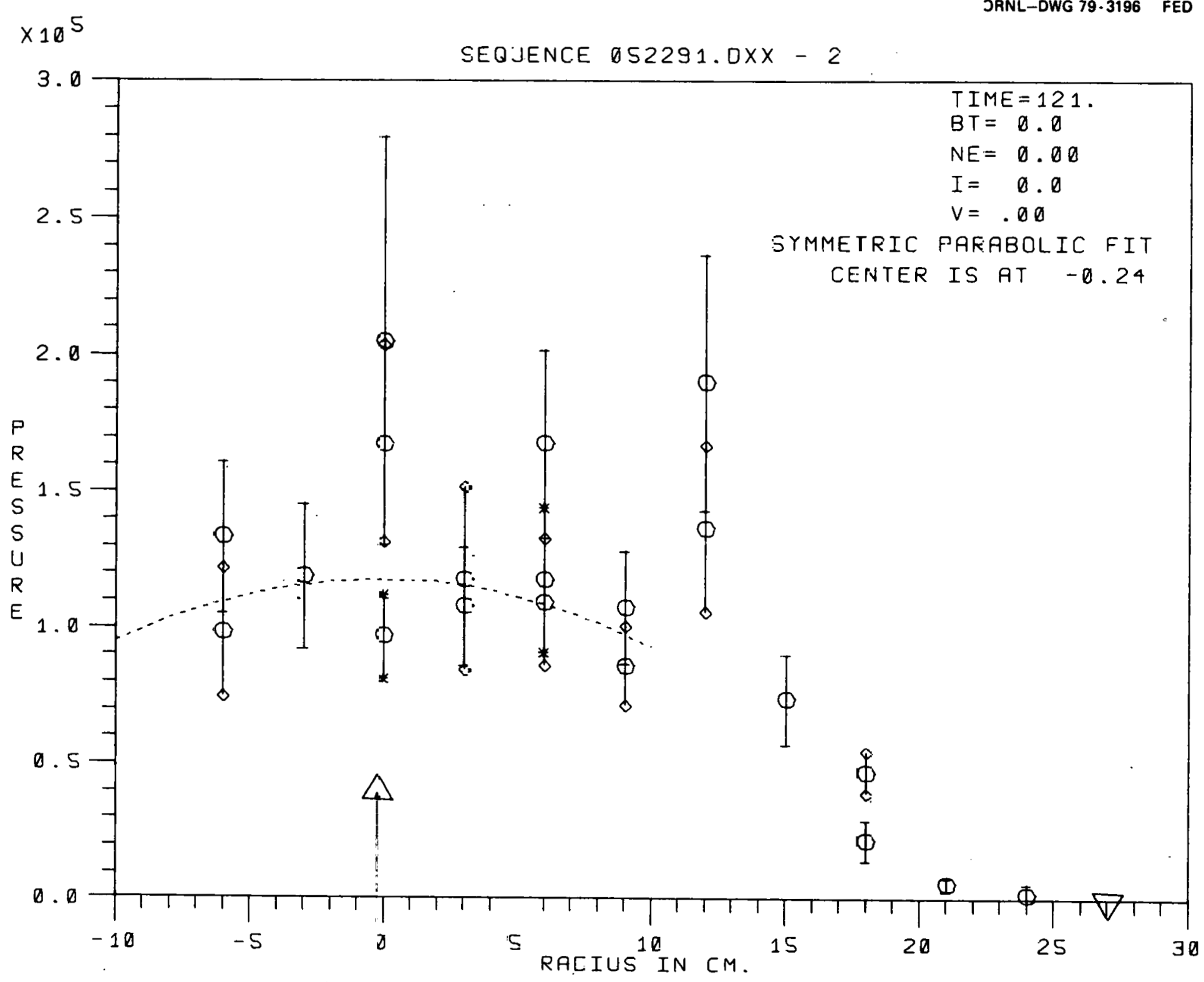

Fig. E.5. Sample output from PROFIT showing a cubic fit of the relative density profile. 


\section{APPENDIX F.}

PROFIL SAMPLE OUTPUT

Sample output from the PROFIL routine is shown for Profile 052291 in Figs. F.1-F.6. 
SEQUENCE DS2291.0XX - 1

$-\cdots-\cdots-\cdots-\cdots-\cdots-\cdots-\cdots \cdots-\cdots$
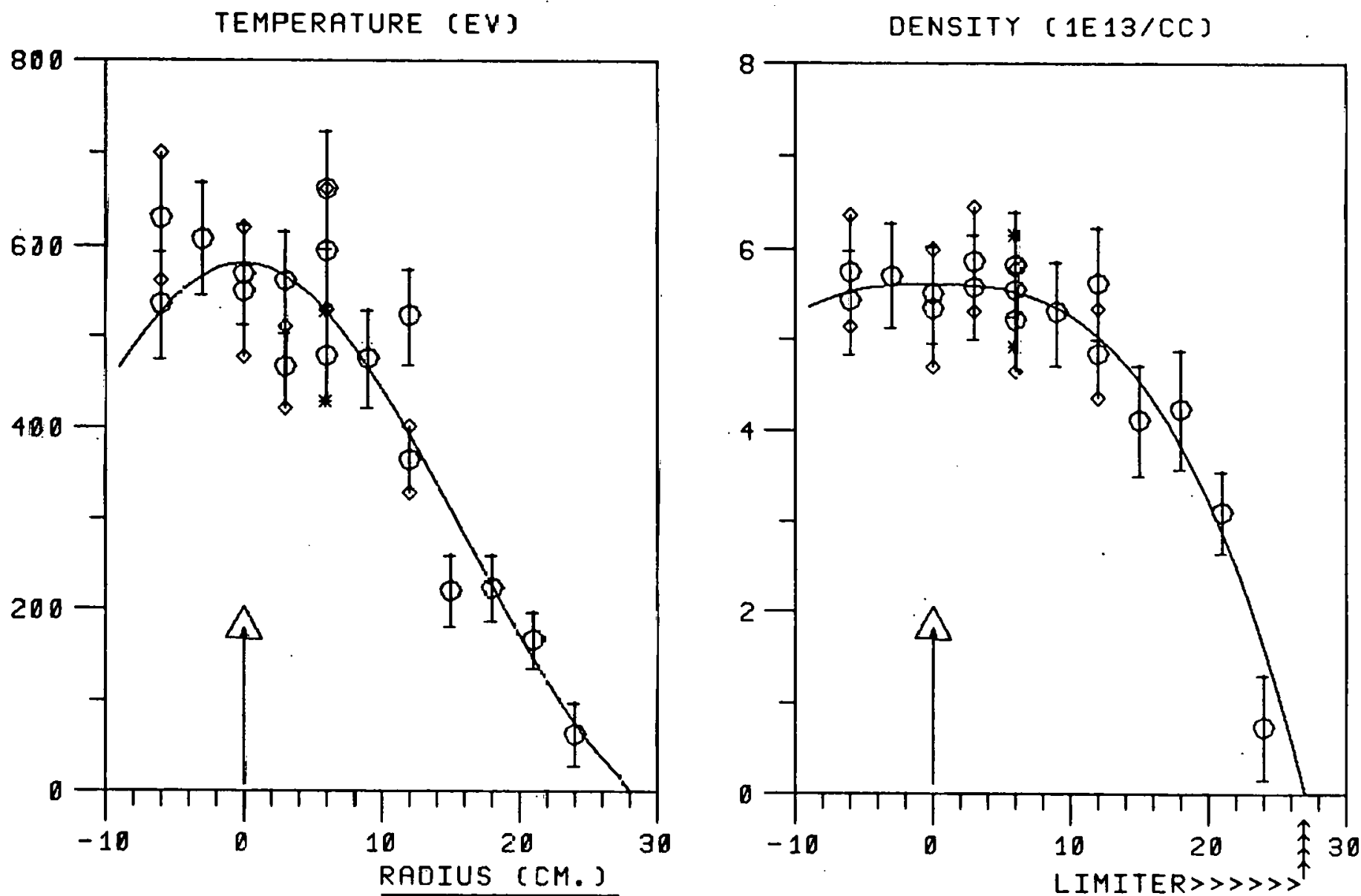

Fig. F.1. Sample output from PROFIl showing temperature and density profiles. 
ORNL-DWG $80 \cdot 2035$

SEQUENCE S2291.DXX - 1

- - - - - - - - - - - - -

(AVERRGES)

TIME $=91 . \quad B T=11.1$

$\mathrm{NE}=3.82$

$I=145.0$

$T I=290.0 \quad V=1.82$
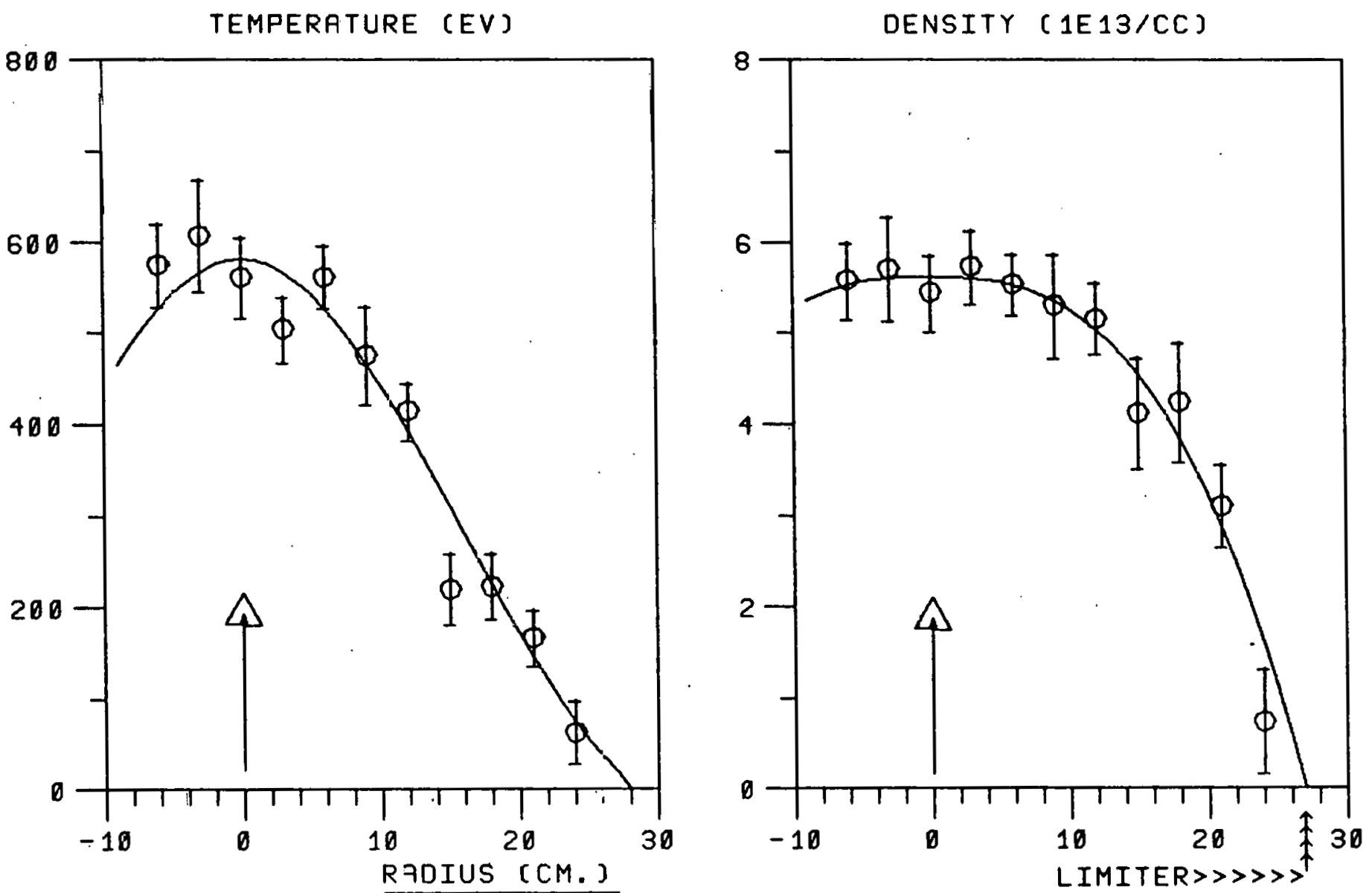

Fig. F.2. Sample output from PRJFIL showing averaged temperature and density profiles. 
THIS PAGE

\section{WAS INTENTIONALLY LEFT BLANK}




\section{APPENDIX G}

\section{ZORDIC SAMPLE OUTPUT}

A small fraction of the sample output from ZORDIC for Profile 052291 is shown in Fig. G.1. 
052291.DXX- 1 ZORDIC (1): CONST.2 - FE IPPJRITY) MMI 19-RUg-79 PAGE 1

WHHOT MUMBER

(a)

- 90.090

MSEC

* $\quad 25.590$

CM

* TajoR Radijs OF PLASMa CENTER - 91.590

CM

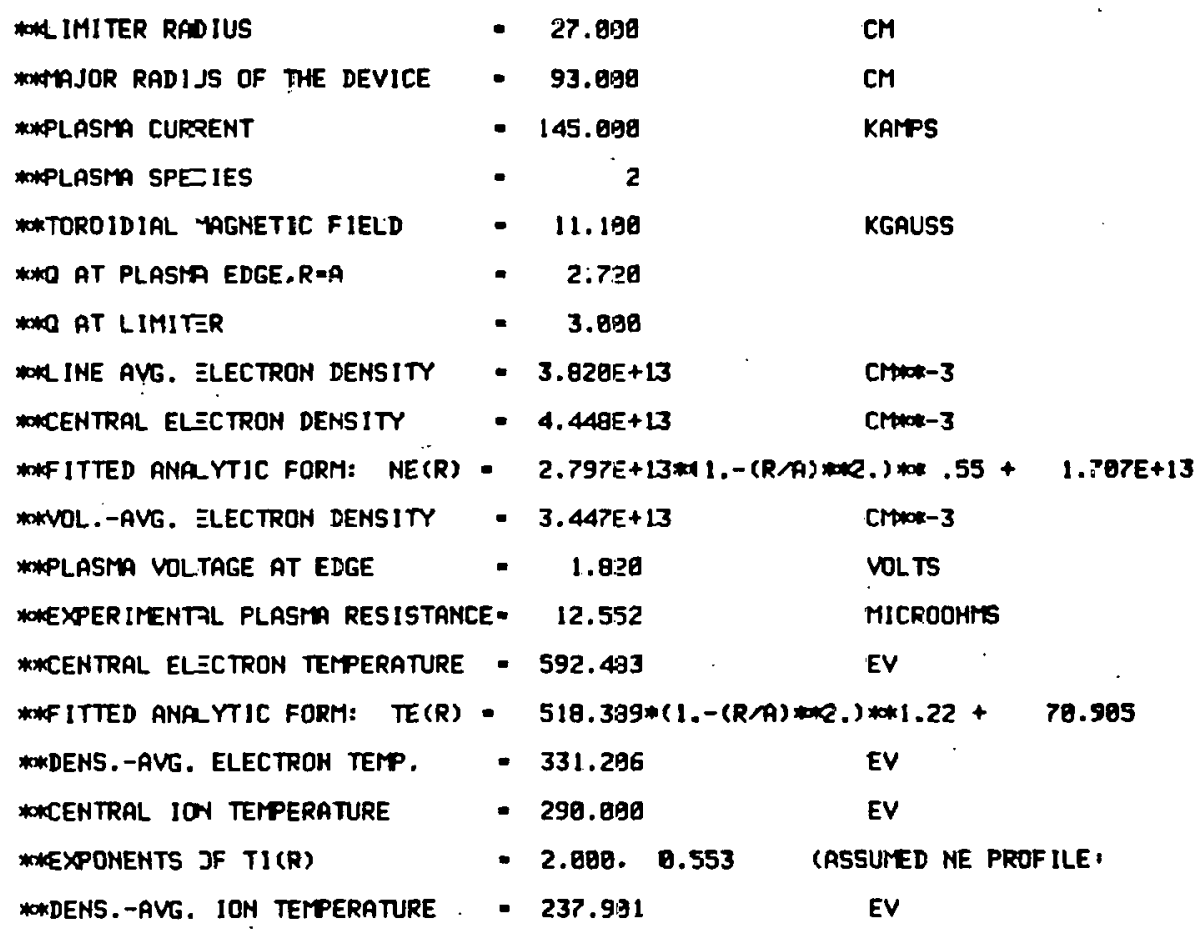

Fig. G.1. (a) Sample output from ZORDIC (p. 1). 


\section{1}

052291.DXX- 1 ZORDIC(1): CDHST.Z - FE IMPURITY) MII 19-AUg-79 PAEE 2

\begin{tabular}{|c|c|c|}
\hline NELECTRON ENERGY CONTENT & - $\quad 3.223 E+03$ & $\mathbf{J}$ \\
\hline * ION ENERGY CONTENT & $=1.989 E+03$ & J \\
\hline * TOTOLL ENERGY CONTENT & - $5.131 E+03$ & J \\
\hline NOHMTIC HEATING POLER & $=263.980$ & KLATTS \\
\hline *OKOTAL INJECTION POWER & 0.080 & KLATTS \\
\hline * IHJ. POLER TO ELECTROH & 0.080 & KLATTS \\
\hline WNIMJ, POLEZ TO ION. & 0.808 & KLAPTTS \\
\hline * ELE. - ION HEAT TRANSFER & .74 .196 & KLATTS \\
\hline
\end{tabular}

\begin{tabular}{|c|c|c|c|}
\hline * RADLATIOM POLER LOSS & - 692.656 & KLATTS -- ASSUMING FE & IMPURITIES RESPONSIBLE FOR ZEFF-1 \\
\hline **CHAMGING RATE OF ELEC. ENERGY & 0.880 & KLATTS & \\
\hline *ELECTRON BETA-POLOIDAL & 0.355 & & \\
\hline *OETA-POLO:DAL & 0.569 & & \\
\hline * & 0.609 & & \\
\hline *WPEAK BETA & 1.228 & PERCENT & \\
\hline WAVERAGE BETA & 0.596 & PERCENT. & \\
\hline * & $-\quad 0.068$ & PERCENT & \\
\hline *NELECTROH ENERGY LIFETITE (OH) & $=12.211$ & MSEC & \\
\hline WELECTRON GERGY LIFETIIE & -12.212 & MSEC & \\
\hline * TOTAL ENERGY LIFETIME & - 19.444 & MSEC & \\
\hline **ION ENERGY LIFETIME(OH) & - $\quad 25.724$ & MSEC & : \\
\hline **ION ENERGY LIFETIIE & $=25.724$ & MEEC & \\
\hline **TAUE FOR TI(R) LIKE ME(R) & - $\quad 19.444$ & MSEC & \\
\hline *NTAUE FOR TI(R) LIKE TE(R) & $=\quad 17.211$ & MSEC & \\
\hline
\end{tabular}

Fig. G.1. (b) Sample output from ZORDIC (p. 2). 
1

\begin{tabular}{|c|c|c|c|}
\hline $052291 . D \times X-1$ & CONST.2 - FE IMPURITY, MMI & 19-Aug-79 & PAGE \\
\hline NONZEFF & 3.381 & & \\
\hline *ZEFF $(\theta)$ ASSUMING $0(\theta)-1$ & 3.584 & & \\
\hline * AT R=B & 0.970 & & \\
\hline *NRADIUS FOR $0-1$ & 1.381 & $\mathbf{C M}$ & \\
\hline * RADIUS FOR 0.2 & - $\quad 20.617$ & CM & \\
\hline *ANUNE MINIMUM & 1.332 & & \\
\hline *NRADIUS FOR NUWE MINIMUM & -11.300 & $\mathrm{CM}$ & \\
\hline HNIUAL RIIIIMUM & 2.565 & & \\
\hline *WRADIUS FOR NU*I HINIHUH & - $17.76 r$ & $\mathrm{CH}$ & \\
\hline *all I &.$\quad 1.012$ & & \\
\hline N INEAR PROTON, DEFICIENCY & 0.836 & & \\
\hline
\end{tabular}

\begin{tabular}{|c|c|c|}
\hline WVL.-AVG. ION DENSITY & - $2.842 E+13$ & cro-3 \\
\hline NOANZ (B) NE (B) & - $0.814 E-03$ & \\
\hline * PSUEDOCLAS. CONF. TIME & 9.644 & MSEC \\
\hline * NENTRAL MEUTRAL DENSITY & - $9.979 E+a 7$ & cran-3 \\
\hline **EDGE MEUTRAL DENSITY & $-5.327 E+10$ & cranos-3 \\
\hline$N * H(R)$ AT $R-\theta$ FOR $E-E(\theta) / 2$ & 0.000 & \\
\hline NOHBEAM IIIDUCED CURREHT & 0.008 & KaMPS \\
\hline hatearta & 0.000 & \\
\hline **DR IFT-VEL. $/$ THERTML-VEL. (AVGD) & - $1.191 E-02$ & \\
\hline *WWIDTH OF MAGNETIC ISLAND & 2.498 & $\mathrm{CM}$ \\
\hline **Y,N MDDE & 2.1 & \\
\hline **R SURFACE &.$\quad 20.622$ & CM \\
\hline *DELTR PRIME & 9.586: & \\
\hline$* * 8$ TILDA & 0.299 . & PERCENT \\
\hline
\end{tabular}

Fig. G.1. (c) Sample output from ZORDIC (p. 3). 
ORNL/TM-7054

Dist. Category $\mathrm{UC}-20 \mathrm{f}$

INTERNAL DISTRIBUTION

1. C. F. Barnett

2. L. A. Berry

3. L. Bighe1

4. A. L. Boch

5. J. A. Cobble

6. E. C. Crume, Jr.

7. R. A. Dory

8. G. R. Dyer

9. P. H. Edmonds

10. L. C. Emerson

11. H. H. Haselton

12. P. N. Haubenreich

13. P. W. King

14-19. E. A. Lazarus

20. M. S. Lube11

21. J. F. Lyon

22. J. T. Mihalczo

23. R. V. Miskel1

24. M. Murakami
25. A. P. Navarro

26. G. H. Neilson

27. 0. B. Morgan

28. V. K. Paré

29. M. W. Rosentha1

30. M. Saltmarsh

31. S. D. Scott

32. J. Sheffield

33. D. Steiner

34. C. E. Thomas, Jr.

35. R. E. Worsham

36-37. Central Research Library

38. Document Reference Section

39-40. Laboratory Records Department

41. Laboratory Records, ORNL-RC

42. ORNL Patent Office

43. Fusion Energy Division Library

44. Fusion Energy Division

Communications Center

EXTERNAL DISTRIBUTION

45. D. J. Anthony, Energy Systems and Technology Division, Genera1 Electric Company, 1 River Rd., Bldg. 23, Room 290, Schenectady, NY 12345

46. C. Breton, DPh-PFC/Service du Confinement des Plasmas, Centre d'Études Nucléaires, B.P. 6, Fontenay-aux-Roses, France

47. N. Biuuks, General Atomlc Co., P.U. Box 81608, San Diego, CA 92138

48. R. W. Conn, Fusion Technology Program, Nuclear Engineering Department, University of Wisconsin, Madison, WI 53706

49. N. A. Davies, Tokamak Branch, Office of Fusion Energy, Department of Energy, Washington, DC 20545

50. S. 0. Dean, Office of Fusion Energy, Department of Energy, Washington, DC 20545

51. H. K. Forsen, Exxon Nuclear Company, Inc., 777 106th Ave., N.E., Bellevue, Washington 98009

52. H. P. Furth, Princeton Plasma Physics Laboratory, P.0. Box 451, Princeton, NJ 08540

53. E. Hinnov, Princeton Plasma Physics Laboratory, P.0. Box 451, Princeton, NJ 08540

54. R. L. Hirsch, Exxon Research and Engineering Co., P.O. Box 101, Florham Park, NJ 07932

55. T. Hsu, Office of Confinement Systems, Office of Fusion Energy, Department of Energy, Washington, DC 20545 
56. H. C. S. Hsuan, Princeton Plasma Physics Laboratory, Princeton University, P.0. Box 451, Princeton, NJ 08540

57. R. Huse, Chairman, EPRI Fusion Program Committee, Public Service Electric and Gas Company, 80 Park Place, Newark, NJ 07101

58. Librarian, Culham Laboratory, Abingdon, Oxon, Ox14 3DB, England

59. H. Ringler, Max-Planck-Institut für Plasmaphysik, 8046 Garching bei München, Federal Republic of Germany

60. S. Suckewer, Princeton Plasma Physics Laboratory, P.0. Box 451, Princeton, NJ 08540

61. R. J. Taylor, Center for Plasma Physics and Fusion Engineering, University of California, Los Angeles, CA 90024

62-66. M. S. Tillack, 5 Highland St., Woburn, MA 01801

67. Office of Assistant Manager, Energy Research and Development, Department of Energy, Oak Ridge Operations Offlce, Oak Ridge, TN 37830

68-259. Given distribution as shown in TID-4500, Magnetic Fusion Energy (Distribution Category UC-20 E: Experimental Plasma Physics) 